\title{
Analysis of GEDI Elevation Data Accuracy for Inland Waterbodies Altimetry
}

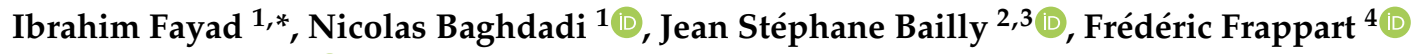 \\ and Mehrez Zribi ${ }^{5}$ (D) \\ 1 CIRAD, CNRS, INRAE, TETIS, University of Montpellier, AgroParisTech, 34093 Montpellier CEDEX 5, \\ France; nicolas.baghdadi@teledetection.fr \\ 2 INRAE, IRD, Institut Agro, LISAH, Univ Montpellier, 34060 Montpellier CEDEX 1, France; \\ bailly@agroparistech.fr \\ 3 AgroParisTech, 75005 Paris, France \\ 4 LEGOS, CNES, CNRS, IRD, UPS-14 Avenue Edouard Belin, Université de Toulouse, 31400 Toulouse, France; \\ frederic.frappart@legos.obs-mip.fr \\ 5 CESBIO (CNRS/UPS/IRD/CNES/INRAE), 18 av. Edouard Belin, bpi 2801, 31401 Toulouse CEDEX 9, France; \\ mehrez.zribi@ird.fr \\ * Correspondence: ibrahim.fayad@inrae.fr
}

Received: 7 July 2020; Accepted: 18 August 2020; Published: 21 August 2020

check for updates

\begin{abstract}
The Global Ecosystem Dynamics Investigation (GEDI) Light Detection And Ranging (LiDAR) altimetry mission was recently launched to the International Space Station with a capability of providing billions of high-quality measurements of vertical structures globally. This study assesses the accuracy of the GEDI LiDAR altimetry estimation of lake water levels. The difference between GEDI's elevation estimates to in-situ hydrological gauge water levels was determined for eight natural lakes in Switzerland. The elevation accuracy of GEDI was assessed as a function of each lake, acquisition date, and the laser used for acquisition (beam). The GEDI elevation estimates exhibit an overall good agreement with in-situ water levels with a mean elevation bias of $0.61 \mathrm{~cm}$ and a standard deviation (std) of $22.3 \mathrm{~cm}$ and could be lowered to $8.5 \mathrm{~cm}$ when accounting for instrumental and environmental factors. Over the eight studied lakes, the bias between GEDI elevations and in-situ data ranged from $-13.8 \mathrm{~cm}$ to $+9.8 \mathrm{~cm}$ with a standard deviation of the mean difference ranging from 14.5 to $31.6 \mathrm{~cm}$. Results also show that the acquisition date affects the precision of the GEDI elevation estimates. GEDI data acquired in the mornings or late at night had lower bias in comparison to acquisitions during daytime or over weekends. Even though GEDI is equipped with three identical laser units, a systematic bias was found based on the laser units used in the acquisitions. Considering the eight studied lakes, the beams with the highest elevation differences compared to in-situ data were beams 1 and 6 (standard deviations of -10.2 and $+18.1 \mathrm{~cm}$, respectively). In contrast, the beams with the smallest mean elevation difference to in-situ data were beams 5 and $7(-1.7$ and $-2.5 \mathrm{~cm}$, respectively). The remaining beams $(2,3,4$, and 8$)$ showed a mean difference between -7.4 and $+4.4 \mathrm{~cm}$. The standard deviation of the mean difference, however, was similar across all beams and ranged from 17.2 and $22.9 \mathrm{~cm}$. This study highlights the importance of GEDI data for estimating water levels in lakes with good accuracy and has potentials in advancing our understanding of the hydrological significance of lakes especially in data scarce regions of the world.
\end{abstract}

Keywords: lidar; GEDI; elevations; lakes; altimetry

\section{Introduction}

Freshwater resources are a renewable resource that is vital for the sustainability of all life forms on Earth. Surface fresh waters, which are found in the form of snow and glaciers, rivers, lakes, 
and reservoirs, are significantly vulnerable to the increasing climate change risks [1]. Projected changes in surface freshwater are region dependent and range from reduced renewable surface water resources to changes in flood magnitude and frequency $[2,3]$. These changes are expected to affect water resources management and intensify the competition for water among agricultural, industrial, energy, and the ecosystem sectors. Currently, 1 billion people depend on lakes for domestic consumption [4], and this figure is estimated to reach 5.5 billion people in the next 20 years [5]. Globally, water is unequally distributed, and water volumes are not constant due to unequal volumes of water-replenishment and water-depletion. Freshwater is replenished through direct rainfall, whereas its consumption is mostly the sum of evaporation, ground seepage, outlet flow and anthropogenic activities, such as irrigation. Therefore, for proper management of freshwater from lakes, rivers, and reservoirs, the monitoring of water volumes and water levels is essential. In general, water surfaces are monitored using in-situ gauge observations. These gauges measure the temporal variations of water levels in lakes, reservoirs, and rivers. However, in-situ monitoring of water levels is scarce and sometimes impractical in many regions of the world due to several reasons: (1) the decline of gauging networks globally due to the cost of installation and maintenance, and their sparsity in developing countries [6]; (2) the limited accessibility and costly charges for acquiring in-situ water level data as they are considered sensitive information [7]; and, finally, (3) the difficulty to monitor water levels across any free water surface, especially in areas where the channel network is not well defined, such as in the case of floodplains and wetlands. In this context, the development of new techniques for the global monitoring of water levels through satellite observations is required.

In the past decades, conventional radar altimeters, which were initially developed for the monitoring of sea and ocean surface topography, have been successfully used for the monitoring and evaluation of water surface height levels of lakes, rivers and wetlands [8-15]. Owing partly to their ability in providing precise water surface elevations over large water bodies, all-weather operability, and global data coverage, radar altimeters are increasingly being used for the monitoring of in-land waterbodies (river, lakes, reservoirs) [16]. To date, there have been thirteen radar altimeter missions (Geosat, ERS-1/2, Geosat Follow-on, Topex/Poseidon, Envisat, Jason 1/2/3, Cryosat-2, HY-2A, Saral/Altika, and Sentinel-3 A and B). Radar altimeter missions are assured with continuity of measurements for the next decade through Jason-Continuity of Service/Sentinel-6 (Jason-CS A in 2020 and Jason-CS B in 2026), Sentinel 3 C and D (planned, respectively, for 2021 and post-2021). Finally, the Surface Water and Ocean Topography (SWOT) will be the first mission to provide elevation maps after 2022 using low incidence Synthetic-Aperture Radar (SAR) interferometry techniques.

To measure surface elevations, a satellite radar altimeter first sends a radar pulse towards the earth, and accurately measures the amount of time it takes the transmitted pulse to be received by the satellite sensor in order to derive the altimetric range (distance between satellite and the reflecting surface). Then, surface elevation is estimated by calculating the difference between the elevation of the satellite that is referenced to an ellipsoid and the altimetric range. However, due to technical reasons, the satellite radar altimeter does not record all the power reflected by all the targets within the instrument window, which can vary between a few hundred meters (Cryosat-2, Sentinel-3) to several kilometers. Instead, satellite altimeters only track a small window within their footprint, in which the size, depending on the satellite mission, can vary between several tens of meters to $1024 \mathrm{~m}$ (Envisat in the $20 \mathrm{MHz}$ ) [15]. Over land areas, surface elevations can vary greatly within the altimeter footprint. Therefore, the surrounding areas of water bodies smaller than the satellite footprint, often contaminates the returned signal. Thus, the accuracy on the estimation of water surface elevations can rapidly decrease from several centimeters for large lakes to several decimeters for small lakes $[9,17,18]$. Recently, with the emergence of new altimeter instruments, such as the altimeters used in ESA's Cryosat-2, and ESA's Sentinel-3 missions, the monitoring of small water bodies should be less problematic. Cryosat-2, as well as the recently launched Sentinel-3 satellite, are equipped with a new Synthetic-aperture radar altimeter (SRAL) instrument, which uses an along-track beam formation in order to generate a smaller footprint strips ( $\sim 300 \mathrm{~m}$ along-track, and $\sim 1 \mathrm{~km}$ across-track). These strips 
can later be superimposed and averaged to improve the elevation estimation accuracy [19]. However, even with the new altimeters, the accuracy of the measurements could still be affected by the size of the water body. For example, for Shu et al. [20], the lowest root mean square error (RMSE) on the water elevation level using the Sentinel-3 altimeter varied between $\sim 4 \mathrm{~cm}$ (bias $=20.89 \mathrm{~cm}$ ) and $\sim 20 \mathrm{~cm}$ (bias $=0.26 \mathrm{~cm}$ ). Huang et al. [21] used Sentinel-3A data to monitor water levels along the Brahmaputra River (rived bed width varies between $\sim 100 \mathrm{~m}$ to more than $1000 \mathrm{~m}$ ). They reported that the standard deviation of the difference between the gauged station recorded water levels and Sentinel-3A derived water levels ranged from 41 to $76 \mathrm{~cm}$. Normandin et al. [22] compared 18 water levels derived from Sentinel-3A with gauge records from 5 in-situ stations in the Inner Niger Delta. Their results showed that with only taking into account the closest ones, the RMSE ranged from $16 \mathrm{~cm}$ to $70 \mathrm{~cm}$. Finally, Bogning et al. [23] found that the RMSE on the estimation of Ogooué river (river bed width varies from $\sim 300 \mathrm{~m}$ to $\sim 1000 \mathrm{~m}$ ) water levels using Sentinel-3 data varied from $41 \mathrm{~cm}$ to $89 \mathrm{~cm}$.

Satellite laser altimeters, similar to conventional radar altimeters, can also be used to measure, and monitor inland water levels. Currently, only three satellite LiDAR missions have been launched. The Geoscience Laser Altimeter System (GLAS) which was carried onboard the Ice, Cloud, and land Elevation Satellite (ICESat-1), was the first operational laser altimeter, and operated between 2003 and 2009 [24]. ICESat-1 carried two laser altimeters operating at visible wavelengths (green and near-infrared), and each near-infrared laser produced $\sim 60 \mathrm{~m}$ footprint on the surface of the Earth at $\sim 170 \mathrm{~m}$ along-track intervals, and firing 40 pulses per second $(40 \mathrm{~Hz})$. The waveform of each GLAS shot is sampled to 544 or 1000 bins over land areas at a temporal resolution of $1 \mathrm{~ns}$. The vertical resolution of waveforms acquired over land is $\sim 15 \mathrm{~cm}$ [24]. ICESat- 1 was succeeded in 2018 by ICESat- 2 that carried the Advanced Topographic Laser Altimeter System (ATLAS). In contrast to GLAS, ATLAS is equipped with a single $532 \mathrm{~nm}$ wavelength laser that emits six beams that are arranged into three pairs. Beam pairs are separated by $\sim 3 \mathrm{~km}$ across-track with a pair spacing of $90 \mathrm{~m}$. The nominal footprint of ATLAS is $17 \mathrm{~m}$ with a spacing interval of $0.7 \mathrm{~m}$ along-track. The most recent spaceborne LiDAR system is GEDI on board the International Space Station (ISS), which launched in December 2018, with on-orbit checkout in April 2019. GEDI's mission is to provide information about canopy structure, biomass, and topography and is estimated to acquire 10 billion cloud free shots in its two years mission [25]. GEDI is comprised of three lasers emitting $1064 \mathrm{~nm}$ light, at a rate of $242 \mathrm{~Hz}$. One of the lasers' output is split into two beams (half the power of the full laser), called coverage beams, while the other two lasers remain at full power. At any given moment, four beams are incident on the ground, where each beam is dithered across track to produce eight tracks of data. The 8 produced tracks, henceforth referred to as beams, are separated by $\sim 600 \mathrm{~m}$ across-track, with a footprint diameter of $\sim 25 \mathrm{~m}$ and a distance between footprint centers of $60 \mathrm{~m}$ along-track [25].

An advantage of laser altimeters for water level monitoring is their small footprint and high-density sampling in comparison to radar altimeters, which makes them more suitable for small water bodies, as the footprint acquired over water is less likely to carry terrain information. However, atmospheric parameters, such as cloud height, cloud thickness, and cloud optical depth, could affect the viability of the echoed LiDAR data [26]. For Abdallah et al. [27], the standard deviation between lake water levels from ICESat-1 GLAS and in-situ water gauge levels was $11.6 \mathrm{~cm}$ (bias $=-4.6 \mathrm{~cm}$ ). In Baghdadi et al. [28], the accuracy (RMSE) to estimate water levels over Lake Geneva was found to be around $5 \mathrm{~cm}$ for footprints that are completely acquired over water, and decreased to about $15 \mathrm{~cm}$ for transitioning footprints (footprints over both terrain and water). However, for very narrow rivers, ICESat-1 GLAS was unsuccessful in determining river water levels, and water level estimated accuracy was around $114 \mathrm{~cm}$ [28].

The objective of this paper was to analyze, for the first time, the quality of GEDI data, with the aim of retrieving water levels of several lakes in Switzerland using the first available GEDI data, that were released in January 2020 for an acquisition period ranging from mid-April 2019 up to mid-June 2019. This paper is organized in five sections. A description of the studied lakes and datasets is given 
in Section 2. The results of the evaluation of GEDI elevations are given in Section 3, followed by a discussion in Section 4. Finally, the main conclusions are presented in the last section.

\section{Study Domain and Datasets}

\subsection{Studied Lakes}

Switzerland has around 1500 lakes. The largest lakes are at the northern foot of the Jura (Lakes Geneva, Neuchâtel and Biel), on the Plateau (Lakes Bodensee, Zurich, and Walensee), in the Lower Alps and the Northern Alps (Lakes Thun, Lucerne, Sempach, Brienz, and Zug), and in the Southern Alps (Lakes Lugano and Maggiore). In addition to these, there exists hundreds of small natural lakes and reservoirs, which can be mainly found in the Alps. In this study, we selected eight lakes in Switzerland (Figure 1). The surface areas of the studied lakes vary greatly between $14 \mathrm{~km}^{2}$, and $528 \mathrm{~km}^{2}$ (Table 1). Three lakes (Geneva, Neuchâtel, and Lucerne) have surface areas greater than $100 \mathrm{~km}^{2}$, and the five remaining lakes have surface areas ranging between 14 and $49 \mathrm{~km}^{2}$ (Walensee, Zürich, Obersee (Zürich), Sempach, and Thun). The average water level elevation for the majority of the lakes is between 405 and $433 \mathrm{~m}$, while Lake Geneva has an average water level elevation of $372.05 \mathrm{~m}$, and Lake Sempach and Lake Thun have an average water level elevations of $503.66 \mathrm{~m}$ and $557.67 \mathrm{~m}$, respectively. Table 1 lists the associated information about the gauge stations, and the number of GEDI acquisitions over each of the eight case study lakes. Lake boundaries have been provided by the Global Lakes and Wetland Databases (GLWD) [29] and will be used to extract the GEDI footprints that were acquired over each of the eight lakes.
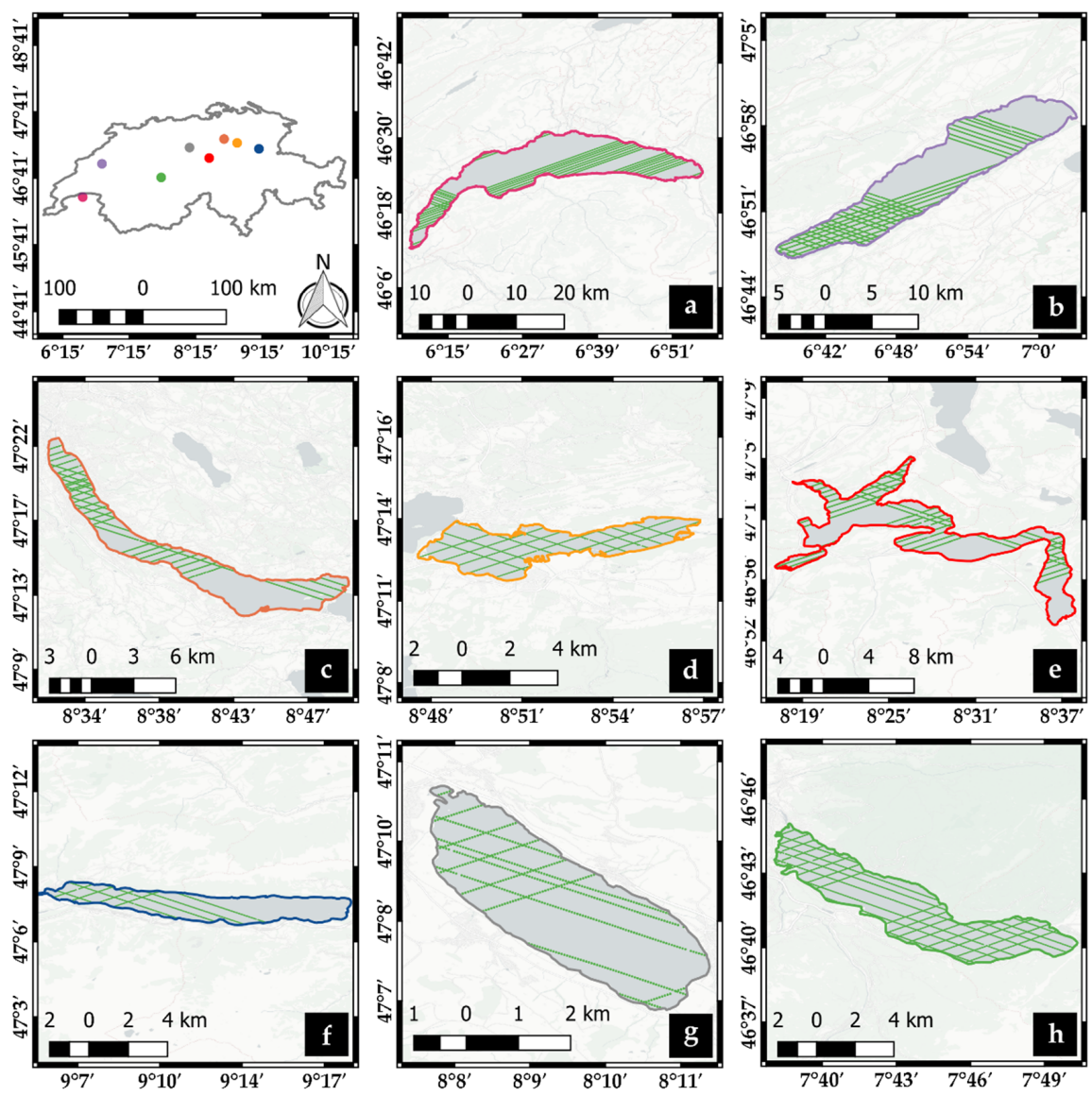

Figure 1. Location of the studied lakes in Switzerland (top left). (a): Geneva; (b): Neuchâtel; (c): Zürich; (d): Obersee (Zürich); (e): Lucerne; (f): Walensee; (g): Sempach; (h): Thun. The green transects represent the GEDI tracks over each lake. 
Table 1. Global Ecosystem Dynamics Investigation (GEDI) acquisition dates between April and June 2019 and available GEDI shot count over the studied lakes. The star $\left(^{*}\right)$ indicates that the average level of water was available for 2018, not 2019.

\begin{tabular}{|c|c|c|c|c|}
\hline Lake & $\begin{array}{l}\text { GEDI Acquisition Dates } \\
\text { dd/mm (Hours) }\end{array}$ & GEDI Shots Count & $\begin{array}{l}\text { Average Water } \\
\text { Level in } 2019 \\
\text { (Gauges) }\end{array}$ & $\begin{array}{c}\text { Approximate Size } \\
\left(\mathbf{k m}^{2}\right)\end{array}$ \\
\hline Geneva & $\begin{array}{c}20 / 04 \text { (08:37); 04/05 (03:12); } \\
28 / 05 \text { (17:23) }\end{array}$ & 7451 & $372.05 \mathrm{~m}$ & 584 \\
\hline Neuchâtel & $\begin{array}{c}21 / 04 \text { (12:37); 28/04 (09:54); } \\
29 / 05(21: 25)\end{array}$ & 5089 & $429.30 \mathrm{~m}$ & 429 \\
\hline Zürich & $\begin{array}{l}02 / 05 \text { (08:08); 04/05 (03:12) } \\
11 / 05(00: 30) ; 08 / 06(13: 10)\end{array}$ & 1711 & $405.91 \mathrm{~m}$ & 49 \\
\hline Obersee (Zürich) & 02/05 (08:08) & 967 & $405.91 \mathrm{~m}$ & 21 \\
\hline Lucerne & 20/04 (08:37); 22/05 (23:59) & 2523 & $433.51 \mathrm{~m}^{*}$ & 113 \\
\hline Walensee & 20/04 (08:37); 02/05 (08:08) & 605 & $419.05 \mathrm{~m}$ & 24 \\
\hline Sempach & $\begin{array}{c}04 / 05 \text { (12:37); } 22 / 05 \text { (23:59) } \\
08 / 06 \text { (13:10) }\end{array}$ & 592 & $503.66 \mathrm{~m}$ & 14 \\
\hline Thun & 20/04 (08:37); 21/04 (12:37) & 2303 & $557.67 \mathrm{~m}$ & 48 \\
\hline
\end{tabular}

\subsection{Datasets}

\subsubsection{In-Situ Water Levels from Gauge Stations}

Water level records from in-situ gauge stations over lakes were obtained free of charge from the Hydrology Department of the Federal Office for the Environment (FOEN) (www.hydrodaten.admin.ch). FOEN currently monitors the quantity and quality of surface water and groundwater through a network of 260 gauging stations across Switzerland. In this study, the comparison between GEDI footprint elevations and the in-situ lake water elevations was done by comparing the footprint elevation at GEDI acquisition time and the reported in-situ daily-mean water level elevation corresponding to the GEDI acquisition date.

\subsubsection{GEDI Data Products}

The Global Ecosystem Dynamics Investigation (GEDI) onboard the International Space Station (ISS), which commenced operations in early 2019, uses three onboard lasers that produce eight parallel tracks (beams) of observations. GEDI lasers illuminate a surface or footprint on the ground with a $25 \mathrm{~m}$ diameter, at a frequency of $242 \mathrm{~Hz}$, over which 2D or 3D structures are measured. The footprints are separated by $\sim 60 \mathrm{~m}$ (center to center) along the beam, and the beams are separated by $\sim 600 \mathrm{~m}$. As the ISS is not maintained in a repeating orbit [25], the repeat cycle of GEDI acquisitions are not guaranteed. However, GEDI has the ability to rotate the instrument up to six degrees, allowing the lasers to be pointed as much as $40 \mathrm{~km}$ on either side of the ISS's ground track [25]. Over our studied lakes, there are on average two acquisition series per lake during the first two months of available GEDI data (Table 1), which correspond to the time period between mid-April 2019 and mid-June 2019. GEDI measures vertical structures using a 1064-nm laser pulse, and the echoed waveforms are digitized to a maximum of 1246 bins with a vertical resolution of $1 \mathrm{~ns}(15 \mathrm{~cm})$, corresponding to a maximum of $186.9 \mathrm{~m}$ of height ranges, with a vertical accuracy over relatively flat, non-vegetated surfaces of $\sim 3 \mathrm{~cm}$ [30].

In order to measure 3D structures, GEDI uses its onboard telescope that collects the light reflected by the ground, vegetation, and even clouds. The collected light, which represents the amount of laser energy reflected from surface objects within the footprint at different heights, is converted to voltage, and recorded as a function of time in $1 \mathrm{~ns}$ intervals. Then, object heights are calculated by multiplying the recorded time by the speed of light, which produces the full-waveform. The recorded waveform can then be used to derive a variety of height metrics, such as vegetation canopy heights, canopy vertical profiles, and relative height (RH, i.e., vertical distribution relative to the ground). 
GEDI is also capable of deriving topographic elevations in the same manner as conventional radar altimeters, i.e., by calculating the range from the surface to the system, which is then converted to the sea surface's height above a reference ellipsoid. Over flat surfaces, such as water surfaces, or bare-grounds, the recorded waveform has a Gaussian form (single peak or mode) similar in shape to the transmitted pulse (Figure 2a). Waveforms recorded within footprints over complex geometries (e.g., forests) will be multi-modal in shape, with each mode representing a reflection from a distinct surface height (Figure 2b). Therefore, in order to precisely estimate water surface elevation, the location of the mode in the waveform, representing the water surface, should be determined as accurately as possible.

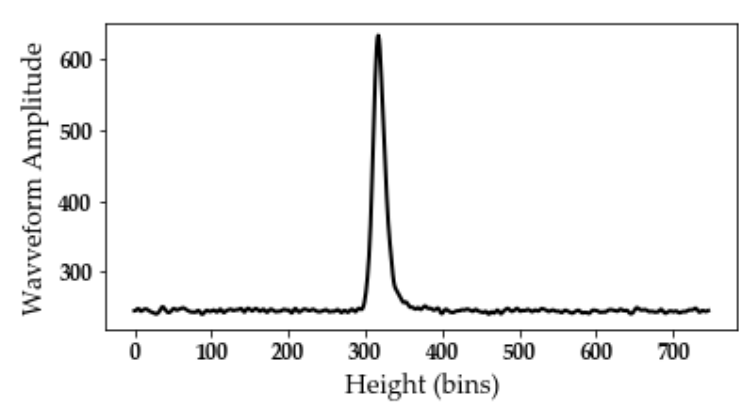

(a)

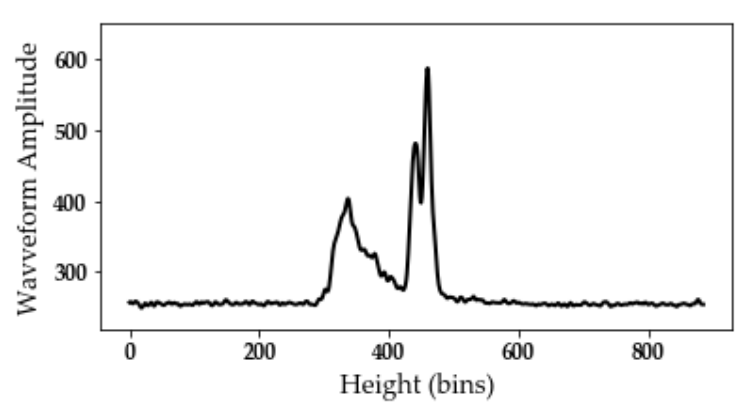

(b)

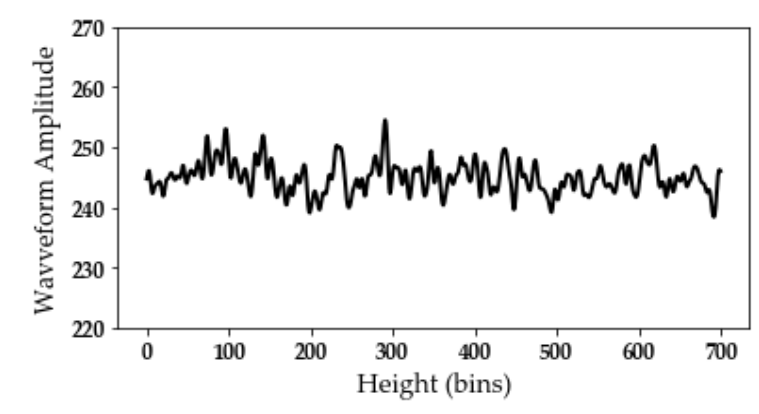

(c)

Figure 2. Typical GEDI waveforms over a lake (a) and a forest stand (b). An unusable waveform due probably due to cloud conditions is shown in (c).

Before any metric can be determined in the received waveforms, the first waveform processing step is, as described in the Algorithm Theoretical Basis Document (ATBD) [31,32], consists in the smoothing of waveforms. Waveform smoothing allows minimizing the noise in the signal, and thus permitting the determination of the useful part of the waveform within the corresponding footprint. Waveform smoothing is performed by means of a Gaussian filter with various widths. As mentioned in the ATBD, currently a width of 6.5 ns was used for the Gaussian filter (smooth width). After smoothing, two locations in the waveform denoted as searchstart and searchend are determined (Figure 3). searchstart and searchend are, respectively, the first and last positions in the signal where the signal intensity is above the following threshold:

$$
\text { threshold }=\text { mean }+\sigma . v
$$

where 'mean' is the mean noise level, ' $\sigma$ ' is the standard deviation of noise of the smoothed waveform, and ' $v$ ' is a variable, currently set at 4 . After determining the locations of searchstart and searchend, the region between them, denoted as the waveform extent, is extended by a predetermined number of sample bins, currently set to 100 bins at both sides. Inside the waveform extent, the highest (toploc) and lowest (botloc) detectable returns are determined (Figure 3). toploc and botloc, respectively, represent 
the highest and lowest locations inside the waveform extent were two adjacent intensities are above a threshold. The threshold equation used to determine toploc and botloc is the same as Equation (1), with ' $\mathrm{v}$ ' an integer fixed to 2, 3, 4, and 6. In the ATBD, the value of ' $\mathrm{v}$ ' used to determine toploc is named 'Front_threshold' and 'Back_threshold for botloc. Currently, six configurations or algorithms, representing different threshold and smoothing settings, were used to determine waveform metrics with high precision in a variety of acquisition scenarios (Table 2). Finally, the location of distinctive peaks or modes in the waveform, such as the ground peak, or top of canopy peaks are determined using a second Gaussian filtering of the waveform section between toploc and botloc, and then finding all the zero crossings of the first derivative of the filtered waveform (Figure 3). The width of the second Gaussian filter (Smoothwidth_zcross) is fixed to either 3.5 or 6.5 ns. Finally, the position of the ground return within the waveform is determined using the position of the last detected peak. Therefore, the geolocation (longitude, latitude, and elevation) of the ground return is interpolated using its offset to the start of the received waveform. The six different algorithms used for the detection of the waveform metrics, generally lead to six different elevations of the ground return. However, since waveforms acquired over water are in general uni-modal waveforms, only two different sets of algorithms produce different elevations. Sets 1 and 4 are similar, and sets 2, 3, 5, and 6 are similar. Therefore, in this study, which is carried on waveforms acquired over water surfaces, only the elevations produced from algorithms 1 and 2 were analyzed.

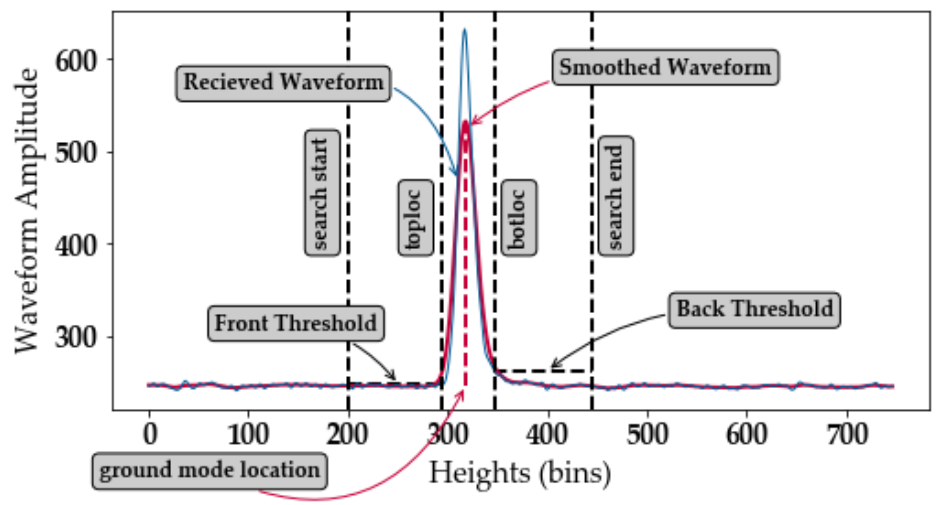

Figure 3. Example of a GEDI waveform acquired over a lake and corresponding waveform metrics; 1 ns corresponds to $15 \mathrm{~cm}$ sampling distance in the waveform.

Table 2. The different parameters used in each of the six algorithms for the interpretation of the received waveforms.

\begin{tabular}{ccccc}
\hline Algorithm & Smooth Width & Smoothwidth_Zcross & Front_Threshold & Back_Threshold \\
\hline 1 & 6.5 & 6.5 & 3 & 6 \\
2 & 6.5 & 3.5 & 3 & 3 \\
3 & 6.5 & 3.5 & 3 & 6 \\
4 & 6.5 & 6.5 & 6 & 6 \\
5 & 6.5 & 3.5 & 3 & 2 \\
6 & 6.5 & 3.5 & 3 & 4 \\
\hline
\end{tabular}

GEDI data used in this study are already processed and published by the Land Processes Distributed Active Archive Center (LP DAAC). Currently, there are three data products (L1B, L2A, and L2B) that are available for download. The L1B data product [30] contains detailed information about the transmitted and received waveforms, the location and elevation of each waveform footprint, and other ancillary information, such as mean and standard deviation of the noise, and acquisition time. The L2A data product [31] contains data of elevation and height metrics of the vertical structures within the waveform. These height metrics are issued from the processing of the received waveforms 
from the L1B data product. Finally, the L2B data product [32] provides footprint-level vegetation metrics, such as canopy cover, vertical profile metrics, Leaf Area Index (LAI), and foliage height diversity (FHD). In this study, the received waveforms, their geolocation (longitude, and latitude), as well as their acquisition times, were extracted from the L1B data product. In the L2A data product, the derived metrics are also grouped by algorithm. Therefore, for each beam, the metrics derived from each of the six algorithms, as well as the parameters used for each algorithm, are available. Therefore, we extracted from L2A for each beam, and for each of algorithms 1 and 2, the following variables: (1) the position within the waveform, as well as the elevation of toploc and botloc, (2) the latitude and longitude, as well as the elevation of the lowest peak or mode, (3) the amplitude of the smoothed waveform's lowest detected mode (zcross_amp), (4) the width of Gaussian fit of the received waveform (rx_gwidth), and (5) the number of detected modes (num_detectedmodes). No metrics were extracted from the L2B data product as they were not relevant to this study.

\subsubsection{Filtering of GEDI Waveforms}

Not all GEDI acquisitions are viable, as atmospheric conditions and clouds can affect them (Figure 2c). Therefore, two filters were applied to remove erroneous lower quality returns. The first filter applied removes waveforms with reported elevations that are significantly higher than the corresponding Shuttle Radar Topography Mission (SRTM) DEM elevation [33] (i.e., we removed all waveforms were $\mid$ GEDI elevation-SRTM $\mid>100 \mathrm{~m}$ ). Since we are only interested with waveforms that are acquired over water, we removed all waveforms having two or more peaks or modes. A multi-modal waveform is a strong indication that the waveform was acquired over areas with complex geometry (e.g., vegetation or considerable relief). Information regarding the number of detected modes for each waveform were acquired from the L2A data product. Over the eight studied lakes, 21242 GEDI shots were available for comparison with the lake gauge data (Figure 1, Table 1). From these shots, only 4637 $(21.8 \%)$ provided exploitable waveforms.

GEDI data accessible through NASA's LP DAAC contain a quality flag (quality_flag) for each acquired waveform. A waveform with a quality flag set to ' 1 ' indicates that the waveform meets certain criteria based on energy, sensitivity, amplitude, and real-time surface tracking quality, and thus can be processed further. However, in this study, after the application of the SRTM DEM filter, waveforms with either value of the quality_flag ( 0 or 1$)$ showed similar characteristics (e.g., defined single peak, high signal to noise ratio, etc.). Therefore, all waveforms were analyzed regardless of the value of the quality_flag.

\subsubsection{Transformation of GEDI Elevations}

In order to conduct a consistent analysis between the elevations provided by GEDI and water elevation from gauge stations, the heights from both datasets must refer to the same vertical datum. In this study, the geolocated GEDI waveform elevations are relative to the WGS 84 ellipsoid, while gauge stations are provided as orthometric heights with reference to the French height system (NGF-IGN69) for lakes Geneva and Neuchâtel, and the Swiss height measurement reference system (LN02) for the other lakes. The tide gauge at Marseille determines the 'zero level' for all elevations in France, while the reference for all height measurements in Switzerland is the "Repère Pierre du Niton" in the harbor of Geneva (stone). The elevation of this stone was evaluated in 1902 to be $373.6 \mathrm{~m}$ over sea level.

The conversion to orthometric heights of GEDI shots acquired over lakes Geneva and Neuchâtel was made using the following equation:

$$
H_{I G N 69}=h_{w g s 84}-N_{I G N 69}
$$

Here, $H_{I G N 69}$ is the derived orthometric height of GEDI footprints from leveling with respect to NGF-IGN69, $h_{w g s 84}$ is the GEDI footprint elevation above the WGS 84 ellipsoid, and $N_{\text {IGN69 }}$ are the French gravimetric geoid heights (e.g., between 48.49 and $50.41 \mathrm{~m}$ for Lake Geneva). The value for 
$N_{\text {IGN69 }}$ was obtained by bilinear interpolation of a $1 \mathrm{~km}$ NGF-IGN69 Geoid Height Grid provided by the French National Institute of Geographic and Forest Information (IGN) (geodesie.ign.fr).

For the remaining lakes, to convert between ellipsoidal elevations and orthometric heights with respect to LN02, a two-step process is required. First, ellipsoidal elevations of GEDI footprints were converted to orthometric elevations with respect to the new Swiss height system LHN95 (Landeshöhennetz 1995) using the following equation:

$$
H_{\text {LHN95 }}=h_{\text {wgs } 84}-N_{\text {CHGEO2004 }}
$$

where $H_{L H N 95}$ is the converted GEDI footprint elevation with respect to LHN05, and $N_{\text {CHGEO2004 }}$ the Swiss gravimetric geoid heights. Then, GEDI footprint elevations, which are now orthometric elevations with respect to LHN95, are converted to the Swiss height system (LN02) by means of three grids. Three grids are required, as height conversion between LHN95 and LN02 cannot be modeled by a single offset. This is due to their different way of gravity reduction, the treatment of vertical movements, and the constraints introduced in LN02. Therefore, the conversion between orthometric LHN95 heights and LN02 heights was made using the following equation [34]:

$$
H_{\text {ln02 }}=H_{L H N 95}+H_{\text {norm }}-H_{\text {scale }}-\frac{\Delta g_{\text {boug }}}{g} H_{L H N 95}
$$

where $H_{l n 02}$ are the GEDI footprint elevations with respect to the Swiss height system (LN02), $H_{\text {norm }}$ is a $1 \mathrm{~km}$ grid describing the difference between LN02 and normal heights, $H_{\text {scale }}$ is a $1 \mathrm{~km}$ grid scale factor used to transform between normal heights and orthometric heights, $\Delta g_{\text {boug }}$ is a $1 \mathrm{~km}$ grid representing the Bouguer anomalies, and $\mathrm{g}$ is the average normal gravity equal to $980,000 \mathrm{mGal}$. The Swiss geoid grid (CHGeo2004), as well as the three grids used in the transformation between LHN95 and LN02 heights, were obtained from the Swiss Federal Office of Topography (www.swisstopo.admin.ch).

\section{Results}

This section will begin with an analysis of two exemplary GEDI waveforms acquired on lakes (Figure 2). Then, the remainder of the results section will analyze the quality of the GEDI elevations for each lake, date, and finally for each beam.

Figure 2a shows a perfect example of a viable GEDI waveform over water surfaces (usable waveform with a high signal-to-noise ratio). The waveform presents a single distinct peak corresponding to the water surface, with very low noise level. In contrast, Figure 2c shows a GEDI waveform with very high noise level and no distinctive peaks, which renders such waveforms useless. The example waveform shown in Figure 2c could correspond to acquisitions in the presence of clouds over our study area.

The comparison between GEDI elevations and in-situ elevations registered from the hydrological gauge stations shows that the parameters used in algorithm a1 (Smoothwidth_zcross of $6.5 \mathrm{~ns}$, Table 2) provide more precise elevations in comparison to algorithm a2 (Smoothwidth_zcross of $3.5 \mathrm{~ns}$, Table 2). Using the entire database from all the lakes in this study (8 lakes and 4637 viable waveforms), GEDI footprint elevations in comparison to in-situ gauge station elevations showed a mean elevation difference of $0.61 \mathrm{~cm}$ with a1 and $7.8 \mathrm{~cm}$ with a2. The standard deviation of the mean difference between GEDI footprint elevations and gauge station readings is $22.3 \mathrm{~cm}$ using a1 and $23.7 \mathrm{~cm}$ using a2. The root mean square error (RMSE) on GEDI elevations is slightly higher using a2 with a value of $24.9 \mathrm{~cm}$ against $22.3 \mathrm{~cm}$ using a1.

\subsection{Analysis of GEDI Waveforms for Each Lake}

The precision of elevations estimated from GEDI waveforms was studied separately for each lake using all GEDI beams from all acquisition dates. Table 3 shows a mean difference (MD) between GEDI and in-situ elevations that varies between $-13.8 \mathrm{~cm}$ (under-estimation by GEDI) and $+9.8 \mathrm{~cm}$ 
(over-estimation by GEDI). The reported standard deviation from MD varied between $14.5 \mathrm{~cm}$ and $31.6 \mathrm{~cm}$.

Table 3. Summary statistics of elevations from GEDI acquisitions for each of the 8 studied lakes (Mean MD, standard deviation std, and root mean square error RMSE of the difference between GEDI elevations and in-situ elevations) using data from all acquisition dates given in Table 1 and from all the beams.

\begin{tabular}{lccccc}
\hline & & \multicolumn{4}{c}{ GEDI-Hydrological Gauges } \\
\cline { 3 - 6 } ID & Lake & $\begin{array}{c}\text { MD } \\
\mathbf{( c m )}\end{array}$ & $\begin{array}{c}\text { Std } \\
\mathbf{( c m )}\end{array}$ & $\begin{array}{c}\text { RMSE } \\
\mathbf{( c m )}\end{array}$ & GEDI Shots Count \\
\hline 1 & Geneva & +0.4 & 14.5 & 14.5 & 319 \\
2 & Neuchâtel & +9.8 & 20.0 & 22.3 & 799 \\
3 & Zürich & -4.4 & 18.7 & 19.2 & 1026 \\
4 & Obersee (Zürich) & -13.8 & 18.1 & 22.8 & 266 \\
5 & Lucerne & +0.9 & 20.6 & 20.6 & 691 \\
6 & Walensee & +5.8 & 15.9 & 16.9 & 547 \\
7 & Sempach & +2.4 & 22.3 & 22.4 & 217 \\
8 & Thun & -1.8 & 31.6 & 31.7 & 772 \\
\hline
\end{tabular}

Figure 4a shows an example of GEDI data for a transect with its 8 beams, acquired on May 29th 2019 at 9:25 p.m. over lake Neuchâtel in Switzerland (GEDI elevations for all lakes can be found in Appendix A, Figure A1). This example shows what has also been observed over the other lakes, albeit with different elevation precision depending on the acquisition date, or beam. Over the transect in Figure $4 \mathrm{a}$, the mean difference (MD) between elevations from GEDI and those reported by the gauge station varied between -6.4 (under-estimation by GEDI) for beam 1 and $+45.2 \mathrm{~cm}$ (over-estimation by GEDI) for beam 6 (Figure 4b). The standard deviation from MD varied between $5.5 \mathrm{~cm}$ for beam 7 and $17.5 \mathrm{~cm}$ for beam 4. Using elevations from all the beams acquired on May 29th 2019 over Lake Neuchâtel, the calculated MD was in the order of $+6.1 \mathrm{~cm}$ (over-estimation by GEDI) with a standard deviation of $16.1 \mathrm{~cm}$. Moreover, over some GEDI footprints, we observed on some beams, elevations that deviated greatly from the mean of all GEDI elevations, with some of these elevations being $50 \mathrm{~cm}$ further from the mean. Despite all verification, we were unsuccessful in explaining the reason for such elevation differences, even though these points were acquired in the middle of the lake, and their corresponding waveforms showed very high signal to noise ratio, and resembled in form to other waveform from other footprints.

\subsection{Analysis of GEDI Waveforms by Date}

Table 4 shows the mean difference and the standard deviation between elevations from GEDI and in-situ gauge records, using data over all lakes, grouped by date. Results show that the mean difference (MD) between elevations from GEDI and in-situ gauges varied between $-26.8 \mathrm{~cm}$ (under-estimation by GEDI) and $+15.2 \mathrm{~cm}$ (over-estimation by GEDI). The lowest bias corresponded to data acquired the mornings of April 28, and May 02 and 04, or late at night on May 22. The highest recorded bias was observed on acquisitions that were made around noon (e.g., April 21, May 28, and June 08), in the early evening (May 29), GEDI acquisitions taken over the weekend (e.g., April 20 and 21, June 08), or before a holiday (e.g., May 22). These strong biases could be due to several phenomenon. (1) Increased perturbations of the water surface due to human activities taking place at these times. The reported standard deviation from MD shows that it varies between $12.7 \mathrm{~cm}$ and 24.9, with a standard deviation lower than $15 \mathrm{~cm}$ for morning acquisitions (e.g., April 28, May 02, and 04), with the exception of June 08, which corresponds to acquisitions taken around noon. (2) Currents generated by thermal effects or winds $[35,36]$. 


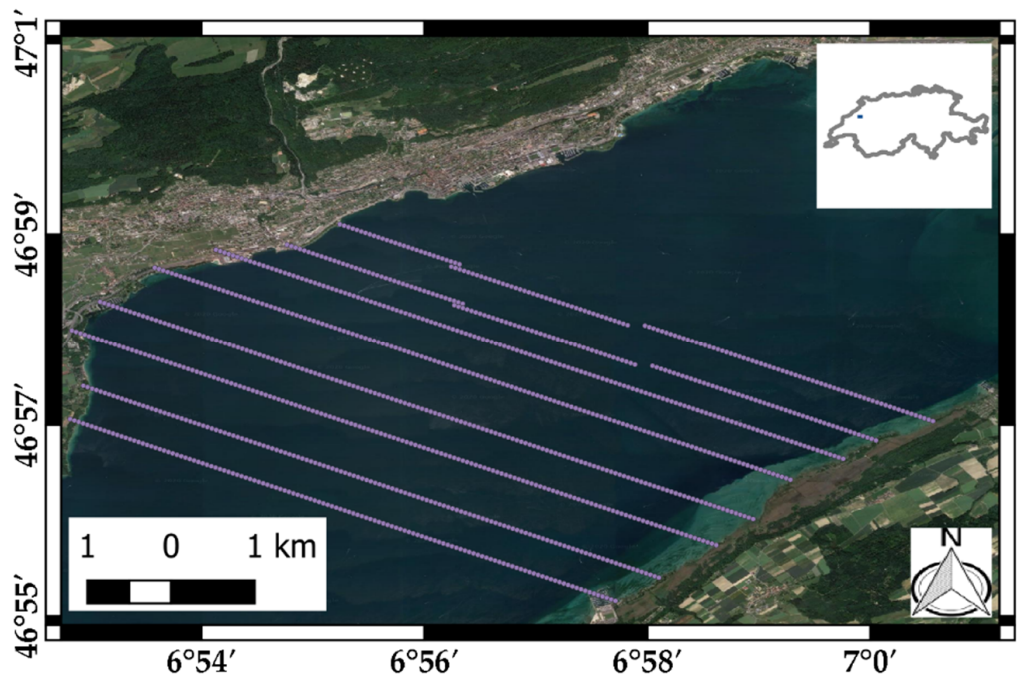

(a)

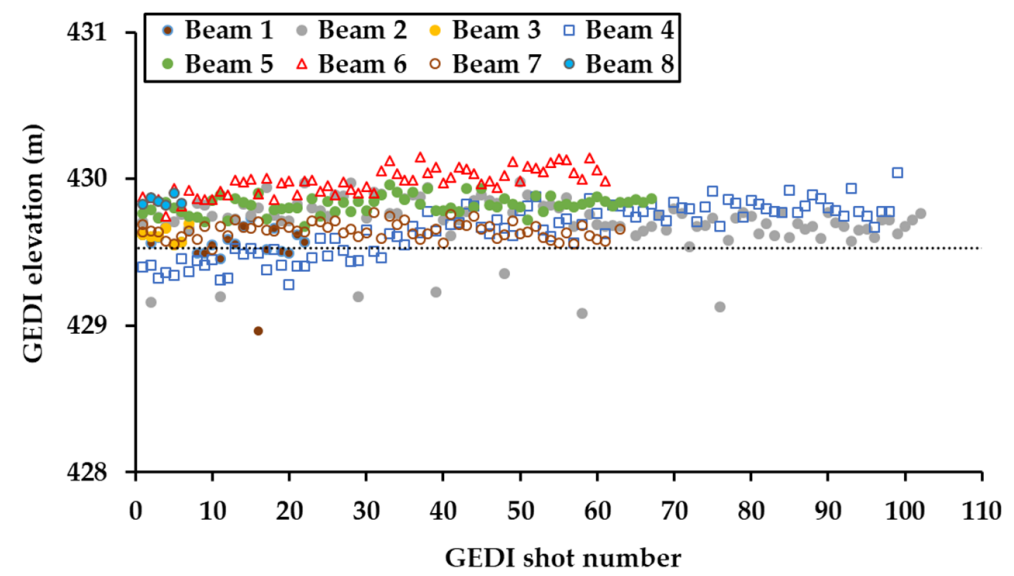

(b)

Figure 4. (a) GEDI shots across Lake Neuchâtel on May 29, 2019. at 21:25 p.m. (b) GEDI elevations of all shots acquired over water plotted for each beam ( 1 to 8$)$. The reference elevation on this date was $429.53 \mathrm{~m}$ (dashed horizontal line). Abscissa = GEDI shot number.

Table 4. Summary statistics (mean MD, standard deviation std, and root mean square error RMSE) of the difference between GEDI and in-situ elevations for all the studied lakes (cf. Table 1) aggregated by date (except for May 11th due to the low number of acquisitions).

\begin{tabular}{|c|c|c|c|c|c|c|c|c|c|c|c|c|}
\hline \multirow{3}{*}{$\begin{array}{l}\text { GEDI } \\
\text { Acquisition Date } \\
\text { dd/mm (hh:mm) }\end{array}$} & \multicolumn{12}{|c|}{ GEDI-Hydrological Gauges } \\
\hline & \multirow{2}{*}{$\begin{array}{l}\text { MD } \\
(\mathrm{cm})\end{array}$} & \multirow{2}{*}{$\begin{array}{l}\text { Std } \\
(\mathrm{cm})\end{array}$} & \multirow{2}{*}{$\begin{array}{c}\text { RMSE } \\
(\mathrm{cm})\end{array}$} & \multirow{2}{*}{$\begin{array}{l}\text { GEDI } \\
\text { Shots } \\
\text { Count }\end{array}$} & \multicolumn{8}{|c|}{ MD by Lake ID (cm) } \\
\hline & & & & & 1 & 2 & 3 & 4 & 5 & 6 & 7 & 8 \\
\hline 20/04 (08:37) & +9.6 & 20.4 & 22.6 & 1005 & 10.7 & - & - & - & -3.6 & 20.8 & - & 13.3 \\
\hline $21 / 04(12: 37)$ & -26.8 & 22.7 & 35.1 & 368 & - & -8.1 & - & - & - & - & - & -38.9 \\
\hline 28/04 (09:54) & +6.5 & 12.7 & 14.3 & 51 & - & 6.5 & - & - & - & - & - & - \\
\hline 02/05 (08:08) & -7.7 & 15.4 & 17.2 & 1358 & - & - & -10.7 & -13.8 & - & 1.0 & - & - \\
\hline $04 / 05(03: 12)$ & -2.3 & 12.9 & 13.1 & 303 & 1.1 & - & -10.3 & - & - & - & -10.7 & - \\
\hline $22 / 05(23: 59)$ & +0.4 & 24.9 & 24.9 & 469 & - & - & - & - & 3.8 & - & -27.4 & - \\
\hline $28 / 05(17: 23)$ & -9.2 & 21.7 & 23.6 & 58 & - & - & - & - & - & -9.2 & - & - \\
\hline $29 / 05(21: 25)$ & +14.4 & 19.2 & 24.0 & 603 & -9.1 & 14.4 & - & - & - & - & - & - \\
\hline 08/06 (13:10) & +15.2 & 14.3 & 20.9 & 401 & - & - & 17.3 & - & - & - & 12.2 & - \\
\hline
\end{tabular}




\subsection{Analysis of GEDI Waveforms by GEDI Beam}

Figure 5 shows the summary of the statistics calculated from the difference between GEDI and hydrological gauge elevations for each date and each beam, using data from all lakes. These statistics were first calculated for each GEDI beam and for each date. Only the statistics with at least 30 GEDI shots for each date/beam pair are reported in this section. Results show that the bias (elevations from GEDI-elevations from gauge stations) varied depending on the acquisition date, and the beam. For certain beams, at certain dates, elevation from GEDI had the same order of magnitude as in-situ elevations, while, for other dates, and even for the same beam, the bias was very significant (Figure 5a). For example, on 20 April 2019, elevations from GEDI acquired over beam 1 showed a bias of $-2.9 \mathrm{~cm}$ which increased to $+21.9 \mathrm{~cm}$ on 8 June 2019. Similarly, Figure $5 \mathrm{~b}$ shows that the standard deviation from the mean difference between GEDI and gauge station elevations varied between $4.6 \mathrm{~cm}$ (beam 6 , 8 June 2019) and $22 \mathrm{~cm}$ (beam 5, 21 April 2019).

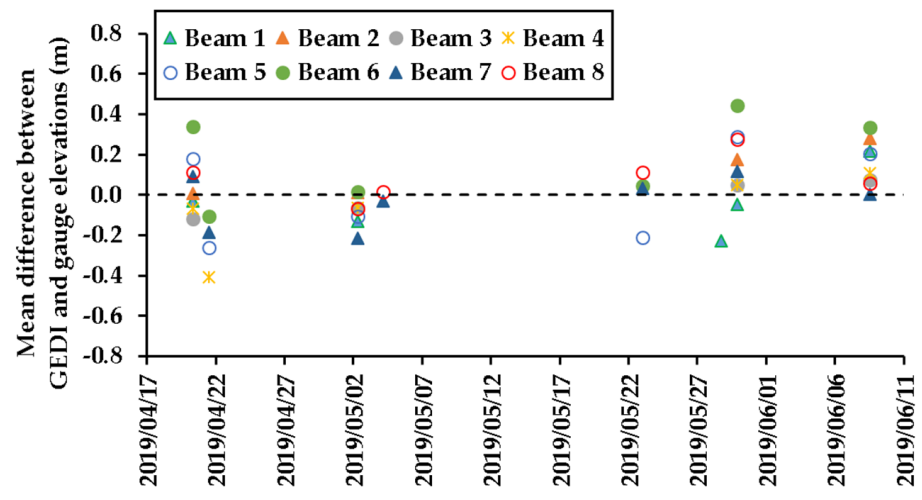

(a)

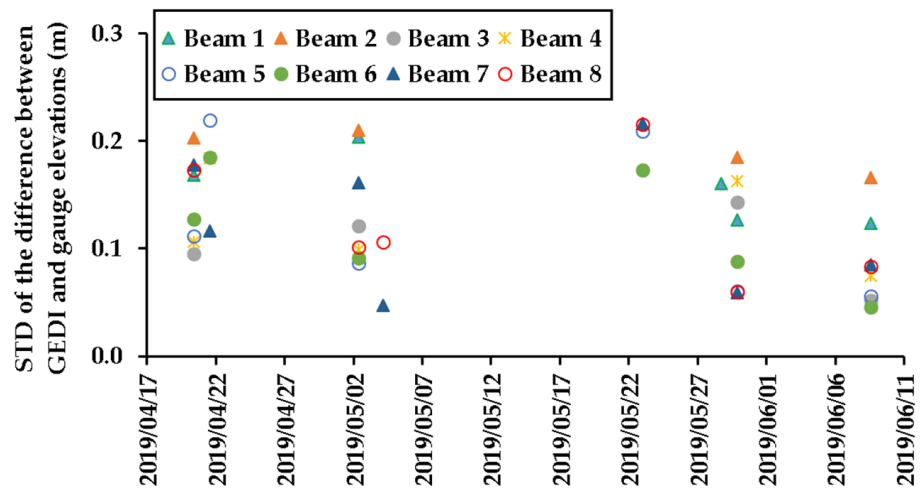

(b)

Figure 5. Mean (a) and standard deviation (b) of the difference between GEDI elevations and hydrological elevations for each date and each beam using data from all lakes.

The statistics were then calculated for each GEDI beam, using all the dates. Results in Table 5 show that the difference between elevations from GEDI and in-situ gauge records differed according to the laser they were acquired with. The mean difference between GEDI and in-situ elevations varied between $-10.2 \mathrm{~cm}$ (under-estimation by GEDI) and $+18.1 \mathrm{~cm}$ (over-estimation by GEDI). The beams with the highest difference were beams 1 (coverage beam) and beams 6 (full power beam) with a mean difference of, respectively, $-10.2 \mathrm{~cm}$ and $+18.1 \mathrm{~cm}$. In contrast, the beams that captured elevations with the smallest diversion from in-situ elevations were beams 5 and 7 (both full power beams), with a mean difference of $-1.7 \mathrm{~cm}$, and $-2.5 \mathrm{~cm}$, respectively, while the remaining beams $(2,3,4$, and 8$)$ show 
the mean observed difference varied between $-7.4 \mathrm{~cm}$ and $+4.4 \mathrm{~cm}$. Finally, the standard deviation from the mean difference between elevations from GEDI and elevations from in-situ gauges were similar across beams, with a standard deviation that varied between $17.2 \mathrm{~cm}$ and $22.9 \mathrm{~cm}$.

Table 5. Summary statistics for each GEDI beam (Mean MD and standard deviation std) for the difference between GEDI and in-situ elevations using all acquired GEDI waveforms (from all acquisition dates over all lakes).

\begin{tabular}{ccccc}
\hline & \multicolumn{4}{c}{ GEDI-Hydrological Gauges } \\
\cline { 2 - 5 } GEDI Beam Number & $\begin{array}{c}\text { MD } \\
\mathbf{( c m )}\end{array}$ & $\begin{array}{c}\text { Std } \\
\mathbf{( c m )}\end{array}$ & $\begin{array}{c}\text { RMSE } \\
\mathbf{( c m )}\end{array}$ & $\begin{array}{c}\text { GEDI Shots } \\
\text { Count }\end{array}$ \\
\hline 1 & -10.2 & 21.8 & 24.1 & 490 \\
2 & +5.5 & 22.9 & 23.6 & 439 \\
3 & -6.6 & 18.1 & 19.3 & 401 \\
4 & -7.4 & 19.4 & 20.8 & 417 \\
5 & -1.7 & 24.8 & 24.9 & 641 \\
6 & +18.1 & 22.8 & 29.1 & 538 \\
7 & -2.5 & 20.0 & 20.2 & 724 \\
8 & +4.4 & 17.2 & 17.8 & 987 \\
\hline
\end{tabular}

Finally, we present an analysis of the distribution of the difference between GEDI elevation estimates for each beam in comparison to in-situ elevations. The difference (D) between GEDI and in-situ elevations has been grouped into five intervals: $(-100,-25),[-25,-10),[-10,+10),[+10,+25)$, and $[+25,+100) \mathrm{cm}$. Figure 6 shows that the lowest elevation differences were obtained using beams 3 , 4 , and 8 . Overall, GEDI elevations from beam 8 were the most accurate, followed by beams 3 and 4 , then beams 1,2, and 7, and finally beams 5 and 6 showed large differences between elevations from GEDI and those from in-situ gauge stations. For beam $8,57 \%$ of the shots had a difference with in-situ elevations between -10 and $10 \mathrm{~cm}$, followed by a small percentage of shots with D between -100 and $-10 \mathrm{~cm}$ and between 10 and $100 \mathrm{~cm}$. For beams 3 and 4, the difference between GEDI and in-situ elevations was between -10 and $+10 \mathrm{~cm}$ for $\sim 50 \%$ of the shots, with a small percentage of shots with D between +25 and $+100 \mathrm{~cm}$ (less than $5 \%)$, and between -100 and $-25 \mathrm{~cm}(\sim 14 \%)$. The difference in elevations $\mathrm{D}$ for beams 1, 2, and 7 was between -25 and $+25 \mathrm{~cm}$ for, respectively, 78,75 and $81 \%$ of the shots. Finally, for beam $6,44 \%$ of the shots showed very high over-estimation of GEDI elevations (D between +25 and $+100 \mathrm{~cm}$ ), while, for beam 5 , the elevation differences were distributed almost equally among the five classes of D. Moreover, results showed that almost $43 \%$ of the shots with an elevation difference $D$ in the range $(-100,-25 \mathrm{~cm}]$ or in the range $[+25,+100 \mathrm{~cm})$ were obtained from beams 5 and 6 (19.7\% from beam 5 , and $22.1 \%$ from beam 6$)$. In contrast, only $5.3 \%$ and $6.5 \%$ of shots in beams 3 and 4 showed an elevation difference $D$ in the range $(-100 ;-25 \mathrm{~cm}]$ or in the range $[+25 ;+100 \mathrm{~cm})$.

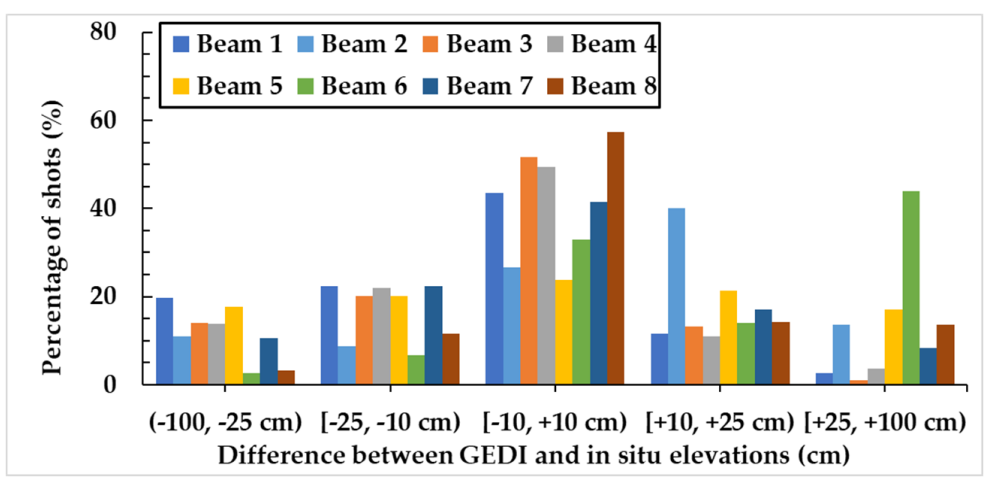

Figure 6. Percentage of GEDI shots for each beam with the difference between GEDI and in-situ elevations (D) grouped intro 5 intervals: $(-100,-25)[-25,-10),[-10,+10),[10,+25)$, and $[25,+100) \mathrm{cm}$. 


\subsection{GEDI Waveform Metrics and Elevation Accuracy}

In this section, we present the effect of some GEDI waveform metrics that could potentially be affected by sensor saturation, and thus have an effect on the GEDI elevation estimations. The correlation between the amplitude of the smoothed waveform at the lowest detected mode (zcross_amp from the L2A product) and the precision on the elevation has been analyzed. This analysis was carried on only two dates (20 April, and 02 May) which had the maximum number of GEDI acquisitions ( 1000 shots for each acquisition date). On April 20th (Figure 7a), the variable zcross_amp varied between 280 and 4000 amplitude counts (AC). For zcross_amp between 280 and 600 AC, the difference D (difference between GEDI and in-situ elevations) increased with zcorss_amp from -50 to about $+40 \mathrm{~cm}$. For zcross_amp between 600 and 3000 AC, the difference D was stable with a value around $+50 \mathrm{~cm}$ for beam 5 and $0 \mathrm{~cm}$ for beam 3. For values of zcross_amp between 3000 and 4000 AC the difference between GEDI and in-situ elevations decreased from $+40 \mathrm{~cm}$ to around $-10 \mathrm{~cm}$. A similar pattern was observed for acquisitions taken on 2 May 2019 (Figure 7b), especially for zcross_amp between 3000 and 4000 AC. For zcross_amp between 600 and 3000 AC on May 2, the difference D was stable and was around $0 \mathrm{~cm}$. However, it decreased to $-60 \mathrm{~cm}$ for zcross_amp around $\sim 4000$ AC. For zcross_amp, less than $600 \mathrm{AC}$, the difference D remained stable but with strong fluctuations for low zcross_amp values (zcross_amp less than $400 \mathrm{AC}$ ). The increased uncertainties for waveforms with higher values of zcross_amp (higher than $3000 \mathrm{AC}$ ) are most probably due to the specular reflection of the water that saturates the detector [29]. Moreover, a large portion of the waveforms with zcross_amp higher than $3000 \mathrm{AC}$ were also observed as having a wider peak which indicates some form of saturation. Indeed, the analysis of the difference D and the width of Gaussian (width of the return peak in the case of unimodal waveforms) fit to the received waveforms ( $r x$ gwidth, available in the L2A data product) shows two clusters (Figure 8). The first cluster corresponds to rx_gwidth values between 4.5 and $9 \mathrm{~ns}$, and the second cluster corresponds to rx_gwidth between 11 and $17 \mathrm{~ns}$. Figure 8 shows that the waveforms from the second cluster have a slight under-estimation of elevations of around $10 \mathrm{~cm}$.

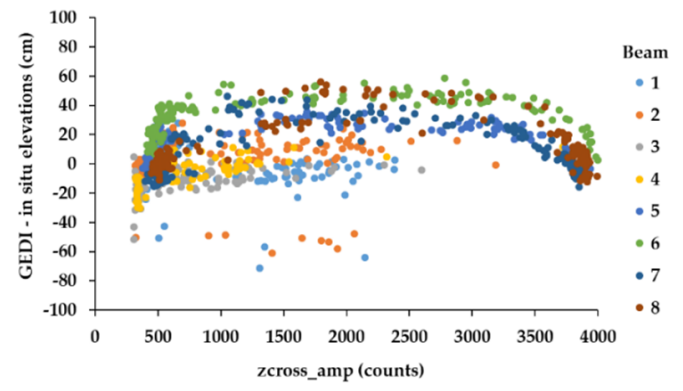

(a)

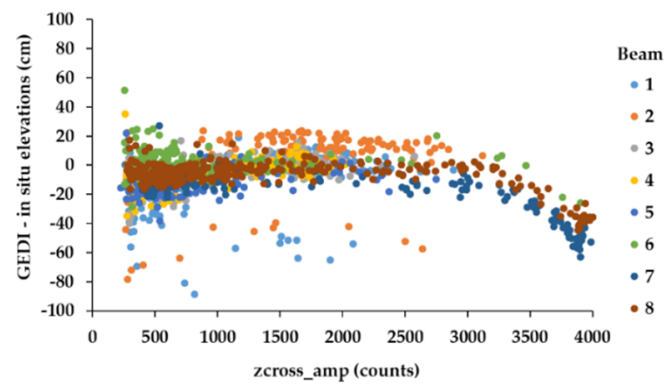

(b)

Figure 7. Difference between GEDI and in-situ elevations as a function of zcross_amp using data from all lakes. (a) 20 April 2020 GEDI acquisitions. (b) 02 May GEDI acquisitions. 


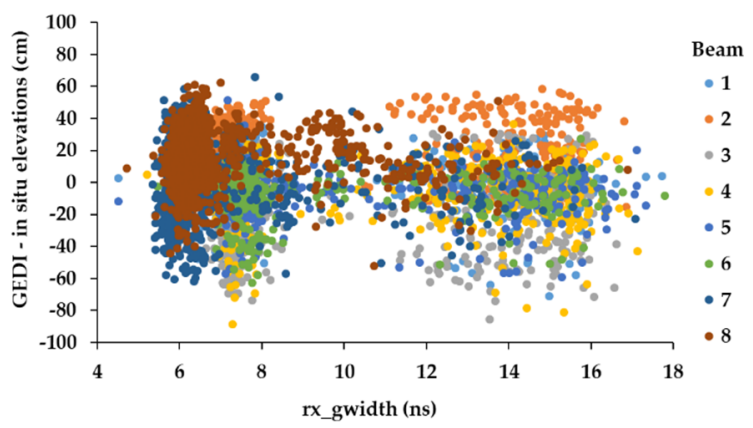

Figure 8. Difference between GEDI and in-situ elevations as a function of rx_gwidth using data from all lakes and all dates.

\subsection{Modelling GEDI Estimation Erorrs}

In the previous sections, we showed that there were several instrumental and environmental factors affecting the acquired GEDI waveforms, thus producing an important difference between in-situ and GEDI estimated elevations. Among these factors, the provided zcross_amp, rx_gwidth from the L2a data product, and the derived GEDI viewing angle $(\theta)$ has been examined. zcross_amp and rx_gwidth were chosen as they are an indicator of saturation as seen in the previous section, whereas the viewing angle has been demonstrated in Urban et al. [37] to increase elevation errors for ICESat-1 GLAS when the viewing angle deviates from nadir due to precision attitude determination. In this paper, the GEDI viewing angle $(\theta)$ has been estimated using the following equation:

$$
\theta=\tan ^{-1}\left(\frac{d}{H}\right)
$$

where $d$ is the distance between an acquired GEDI shot and the position of GEDI projected at nadir onto the WGS84 reference ellipsoid and $H$ is the elevation of GEDI over the referenced ellipsoid.

In addition to the previous factors, several additional environmental factors have also been considered since in-situ water levels do not necessarily provide water elevation across the surface of lakes as standing waves (seiches), and wind-generated waves are commonly present over lakes. Over the studied lakes, no direct information about waves were available, therefore, they were substituted by proxy variables. In essence, we chose the factors that influence the creation and the form of standing, and wind-generated waves (e.g., wave heights and wave direction). These factors include wind speed, wave direction, and lake depth. Wind speeds were acquired at each GEDI acquisition date using meteorological data from the nearest weather stations. Wave direction and average lake depth at each GEDI footprint were acquired from the LATLAS project (swisslakes.net) using GEDI footprint coordinates for lake depth, and wind direction and GEDI footprint coordinates to determine the wave direction. Nonetheless, these factors were only available for five of the eight studied lakes (Geneva, Neuchâtel, Zürich, Obersee (Zürich), and Lucerne).

In Section 3.2, it was shown that GEDI acquisition dates and times could influence the accuracy of GEDI elevation estimates. Therefore, two additional factors were considered for the modelling of GEDI estimation errors. (1) The acquisition time of a GEDI shot (Time of Day, TOD) was converted to a value between 1 and 3 representing, respectively, acquisitions taken in the morning ( 6 a.m. to 12 a.m.), afternoon (12 a.m. to 6 p.m.), and evening (6 p.m. to 12 p.m.). (2) The acquisition date of a GEDI shot was converted to a value between 1 and 7 representing the acquisition day (Day of Week, DOW).

Finally, GEDI estimation errors were modeled using the previously mentioned factors in a Random Forest regressor (RF). Random Forests are an ensemble of machine learning algorithms used for classification or regressing by fitting a number of decision trees on various sub-samples of the dataset, and uses averaging to improve the predictive accuracy and control over-fitting [38]. Compared to linear models, RF is advantageous for being able to model also nonlinear relationships (threshold 
effect) between the variable to explain and the explanatory variables. For this study, the number of trees in the RF were set to 100 trees, with a tree depth equal set to the square root of the number of available factors. In order to train and assess the model accuracy, we randomly split the database into $70 \%$ for training and $30 \%$ for validation (and accuracy estimation).

The random Forest regression results for the five lakes combined showed that we were able to explain $\sim 82 \%$ of the error (GEDI—in-situ elevations) variance and reduce the RMSE on the elevation estimation from 20.2 to $8.4 \mathrm{~cm}$ (Figure 9).

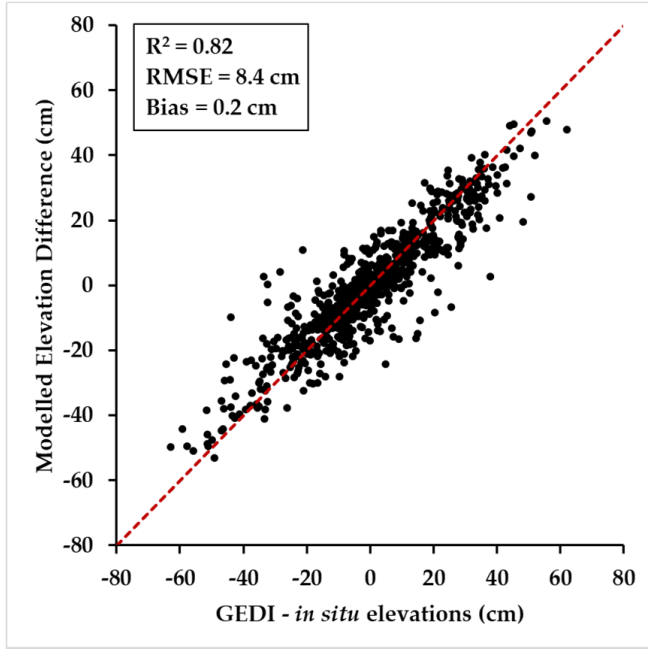

Figure 9. Comparison between the modeled elevation difference as a function of instrumental and environmental factors and the obtained elevation difference between GEDI and in-situ elevations.

Moreover, the factors that contributed the most on the difference between GEDI and in-situ elevations were determined. This process was conducted using the percentage increase in the mean square error of the regressions (\%IncMSE, estimated with out-of-bag cross validation) from the factor importance test for the random forests model (average and standard deviations of 50 repetitions) (Figure 10). The factor importance test shows that the most important factors for the modeling of errors is related to the viewing angle of GEDI $(47.6 \%)$, followed by zcross_amp (47.2\%) wave direction $(45.5 \%)$, depth $(43.5 \%)$, wind speed $(40.2 \%)$, and rx_gwidth $(30.2 \%)$. The least important factors are the effect of the acquisition time (TOD 22.3\%) and date (DOW 18.0\%).

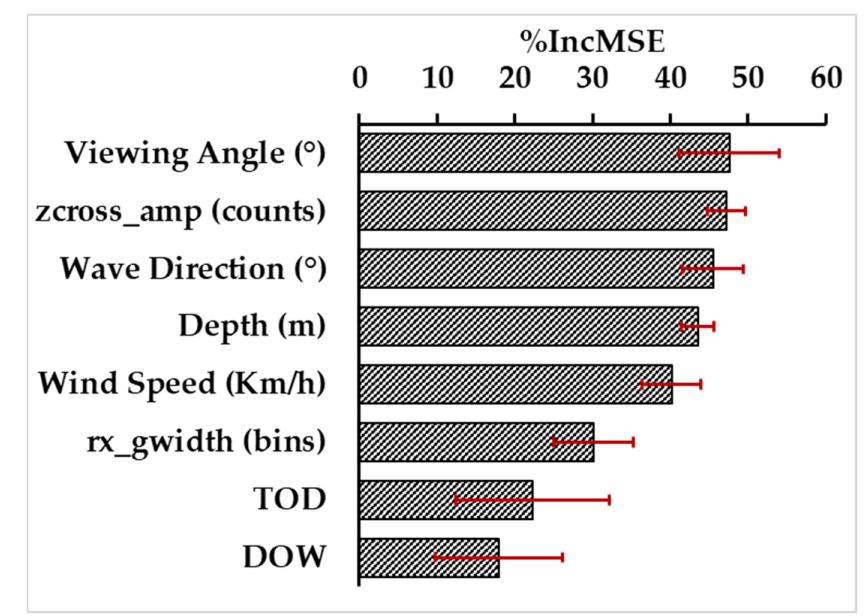

Figure 10. Variables' order of importance in the error estimation random forest regression model with the \%IncMSE (higher values mean higher importance). 
The modeling of GEDI errors for each lake separately did not show any differences specific to the location, geography, or geometry of the lake. For the five lakes tested, the random forest regressor was able to explain between 70.1 to $83.3 \%$ of the error (GEDI-in-situ elevations) variance, with an accuracy on the GEDI elevations between 5.6 and $10 \mathrm{~cm}$ (Table 6).

Table 6. Accuracy of elevations from GEDI acquisitions for each of the 5 lakes without and with accounting for the sources of error (RMSE), using data from all acquisition dates given in Table 1 and from all the beams.

\begin{tabular}{|c|c|c|c|}
\hline \multirow{2}{*}{ Lake } & \multirow{2}{*}{$\begin{array}{c}\text { Error Modelling } \\
\text { Coefficient of } \\
\text { Determination }\left(R^{2}\right)\end{array}$} & \multicolumn{2}{|c|}{ GEDI-Hydrological Gauges } \\
\hline & & $\begin{array}{l}\text { RMSE Before } \\
\text { Correction (cm) }\end{array}$ & $\begin{array}{c}\text { RMSE After } \\
\text { Correction }(\mathrm{cm})\end{array}$ \\
\hline Geneva & 75.8 & 14.5 & 5.6 \\
\hline Neuchâtel & 70.1 & 22.3 & 10.0 \\
\hline Zürich & 75.0 & 19.2 & 9.6 \\
\hline Obersee (Zürich) & 76.7 & 22.8 & 7.6 \\
\hline Lucerne & 83.3 & 20.6 & 9.0 \\
\hline
\end{tabular}

\section{Discussion}

Using GEDI data extracted from the algorithms developed by the GEDI team, the accuracy of the GEDI water surface elevation estimates seems to be high enough. Overall, the standard deviation from the mean difference between GEDI and in-situ elevations is $\sim 22 \mathrm{~cm}$ with no apparent bias. Moreover, given GEDI's small footprint diameter $(25 \mathrm{~m})$, GEDI should provide better elevation estimates in comparison to, for example, radar altimeters for narrower water surfaces, such as rivers. On the other hand, while GEDI uses the same laser specs as those used for GLAS on board ICESat-1, the precision obtained by GEDI is inferior to that obtained using ICESat-1. In fact, Baghdadi et al. [29] in their study over Swiss lakes, observed an accuracy (RMSE) of elevation estimates in the order of $\sim 5 \mathrm{~cm}$ using ICESat-1 data.

GEDI's smaller footprint means that GEDI waveforms within the footprints could easily be affected by small disturbances coming, for instance, from water surface roughness, which leads to uncertainties in the estimation of water surface elevations. For example, GEDI acquisitions with the highest mean difference to in-situ elevations, and highest standard deviation were acquisitions taken during the weekend (e.g., April 21, June 08), or before a holiday (e.g., May 22). The uncertainties at these acquisition dates could be explained in part by the increased human activities over the water surface (e.g., ships) which pollutes the return waveform. Moreover, these uncertainties are also the result of small currents generated by thermal effects [35] or winds [36], that disrupts the water surface. Finally, over large lakes, water surface is not entirely flat due to the presence of wind-generated waves and seiches. Therefore, GEDI, depending on the angle of incidence, can over- or under- estimate the water surface level by providing elevations from the trough or the top of the waves. In our study of the effects of GEDI's viewing angle over each lake and each date, we observed that, generally, uncertainties on the estimation of elevations increased with increasing viewing angle. Moreover, the acquisitions with the large deviation to the mean elevation difference between GEDI and in-situ elevations were acquisitions with the largest viewing angle.

The time of GEDI acquisitions also introduces uncertainties on the elevation estimates. For example, during sunlit GEDI acquisitions, photons from the sun reflecting at the water surface could contaminate the returned echo and increase the noise. In this study, we found that GEDI elevation estimates with the lowest standard deviation and bias to the in-situ elevations were acquisitions taken during the morning or late at night when lake water surfaces are usually calm, cooler with low wind speeds. For these acquisition times (April 28 and May 02, 04, and 22), the mean difference between GEDI and in-situ elevations was $-6 \pm 15 \mathrm{~cm}$. 
The analysis of the precision of elevations from GEDI according to the used laser in the acquisition did not show any difference between coverage and full power laser. Nonetheless, some beams showed systematic differences in comparison to others. In general, the most accurate elevations came from beams 1-4 (coverage laser) and beams 7-8 (full power laser). Beams 5-6, which also correspond to a full power laser, showed the least precise elevations across all dates. Moreover, there were some differences on the elevation estimation accuracies across the beams. For example, footprints acquired from beam 8 had better precision than footprints from beam 7, albeit both beams are produced using the same laser unit onboard GEDI. Similar observations have been noted for beams 3 and 4, which were found to be more precise than beams 1 and 2. However, these uncertainties could be mostly explained by the errors introduced from the viewing angle of GEDI, which differs from one beam to another on a given acquisition date.

In general, the differences between GEDI and in-situ elevations are due to both instrumental and environmental factors. In our modeling of the errors, the two most contributing factors were the viewing angles of GEDI, and the saturation on some of the acquired waveforms assuming this occurs through the zcross_amp indicator. However, these factors could be corrected in unimodal waveforms. Another form of uncertainties is related to the uneven water surface due to standing and wind-generated waves. This was apparent by the high contribution of environmental factors, like the wave direction, depth of the lake at each GEDI footprint, and the wind speed. Lake depth is a direct indicator of the wave heights as waves near the shore (low depth) are higher than waves farther away, while wind speed controls the height of the generated wave. In this study, the contribution of wind speed on the errors appears to be lower than other factors. However, this is due to the low wind speeds at the present GEDI acquisition (maximum encountered wind speed of $12 \mathrm{~km} / \mathrm{h}$ ), which suggests small wind-generated waves. In addition to instrumental and environmental factors, the acquisition date and time of GEDI can also directly affect its accuracy. The time of the acquisition during the day, as well as the day of the week on which an acquisition took place, both can have effects on the echoed waveforms as seen previously. The effect of these two factors is related to the noise from the sun on the GEDI receiver, and the increased human activities over each lake during certain days.

Finally, the provided quality_flag from the L1B data product could help, in theory, to select GEDI data with higher accuracy on elevations. Using data issued after the application of our filter (ISRTM elevation-GEDI elevation| > $100 \mathrm{~m}$ ), we observed only a slight decrease of the root mean square error on GEDI elevation estimates when we considered only the waveforms with a quality_flag $=1$. For algorithm a1, we observed a decrease in the RMSE of around $1.4 \mathrm{~cm}$ (from $22.3 \mathrm{~cm}$ using data with both quality_flag $=0$ and 1 to $20.9 \mathrm{~cm}$ using only quality_flag =1). Similarly, for a2, the decrease in the RMSE was around $0.8 \mathrm{~cm}$ (from $24.9 \mathrm{~cm}$ using data with both quality_flag $=0$ and 1 to $24.1 \mathrm{~cm}$ using only quality_flag = 1).

\section{Conclusions}

In this study, we analyzed GEDI data in order to determine its accuracy of elevation estimation over lake surfaces using algorithms provided by the Land Processes Distributed Active Archive Center (LP DAAC). The objective was to study the quality of the first two months of GEDI data (min-April until mid-June 2019) acquired over several lakes in Switzerland. Overall, 4367 GEDI shots out of 21,242 available shots were exploitable and analyzed over the eight studied lakes.

This first analysis of GEDI data from the first two months of acquisitions showed a very low mean elevation difference between GEDI and in-situ gauge station elevations, in the order of $0.61 \pm$ $22.3 \mathrm{~cm}$ for one standard deviation. While GEDI's reported vertical accuracy in this study was well below the $50 \mathrm{~cm}$ vertical accuracy provided in Dubayah et al. [31], it still remains higher than what was previously obtained using the ancient LiDAR satellite ICESat-1. In fact, the vertical accuracy of GLAS onboard ICESat-1 was better than $10 \mathrm{~cm}$, as demonstrated by Baghdadi et al. [29]. 
The analysis of GEDI data by lake showed that the vertical precision varied from under-estimation by GEDI of $-13.8 \mathrm{~cm}$ for certain lakes, to over-estimations of $+9.8 \mathrm{~cm}$ for others, with a varying standard deviation between 14.5 and $31.6 \mathrm{~cm}$.

The investigation of GEDI's vertical accuracy by date showed a mean difference between GEDI and in-situ gauge station elevations varying between -26.8 and $+15.2 \mathrm{~cm}$. The lowest bias corresponded to data acquired in the morning or late at night. The highest recorded bias was observed on acquisitions that were made around noon, in the early evening, and over the weekend. Moreover, the difference in GEDI's elevation accuracy according to the acquisition date is also affected, in part, by the instrument's viewing angle at acquisition time (larger viewing angle leads to lower accuracies). However, the full effects of the viewing angle were not studied in its entirety due to the small number of available acquisitions at the time of this writing.

The analysis of GEDI data by beam number showed that the difference between GEDI and gauge stations' elevations varied depending on the acquisition date and the beam. Certain beams at certain dates showed that elevations from GEDI were very similar to in-situ readings (fluctuations of few $\mathrm{cm})$. Summary statistics calculated for each GEDI beam using acquisitions from all dates showed that the beams with the highest elevation differences to in-situ readings were beams 1 and $6(-10.2$ and $+18.1 \mathrm{~cm}$, respectively). In contrast, the beams with the smallest mean elevation difference to in-situ readings were beams 5 and $7(-1.7$ and $-2.5 \mathrm{~cm}$, respectively). The remaining beams $(2,3,4$, and 8$)$ showed a mean difference between -7.4 and $+4.4 \mathrm{~cm}$. The standard deviation of the mean difference, however, was similar across all beams (between 17.2 and $22.9 \mathrm{~cm}$ ).

The analysis of the metrics, such as the amplitude or width of the modes, did not allow further investigation of GEDI elevation estimation accuracy, even though a certain dependence was found between these metrics and the quality of GEDI data.

Nonetheless, accounting for instrumental and environmental factors increased the accuracy (RMSE) of GEDI estimates to $8.4 \mathrm{~cm}$ for all lakes and from 5.6 to $10 \mathrm{~cm}$ (with no apparent bias) when modeling the errors for each lake independently.

Following the first analysis done on the first GEDI data sets, we can conclude that GEDI has a strong potential for precise estimation of water surfaces of any size. Moreover, a better estimate of GEDI metrics by the LP DAAC can be expected in the near future, allowing for reprocessed data with a better elevation precision.

Author Contributions: Conceptualization, I.F. and N.B.; Data curation, I.F.; Formal analysis, I.F., N.B. and J.S.B.; Investigation, I.F., N.B. and F.F.; Methodology, I.F., N.B.; Software, I.F.; Validation, I.F., N.B., J.S.B., F.F. and M.Z.; Writing—original draft, I.F.; Writing-review \& editing, I.F. and N.B. All authors have read and agreed to the published version of the manuscript.

Funding: This research received funding from the French Space Study Center (CNES, TOSCA 2020 project), the Research Infrastructure IR Data Terra, and the National Research Institute for Agriculture, Food and the Environment (INRAE).

Acknowledgments: The authors would like to thank the GEDI team and the NASA LPDAAC (Land Processes Distributed Active Archive Center) for providing GEDI data. The authors would also like to thank the Swiss Federal Office for the Environment (FOEN) for providing the national gauge database.

Conflicts of Interest: The authors declare no conflict of interest. 


\section{Appendix A}

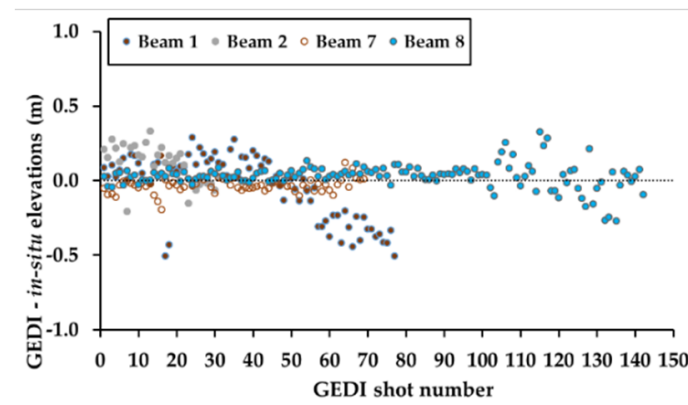

(a)

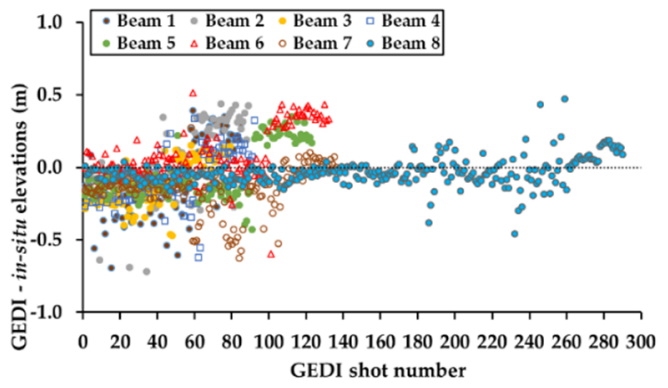

(c)

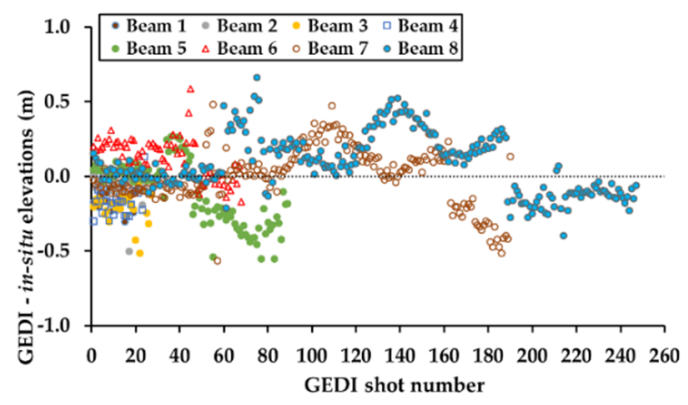

(e)

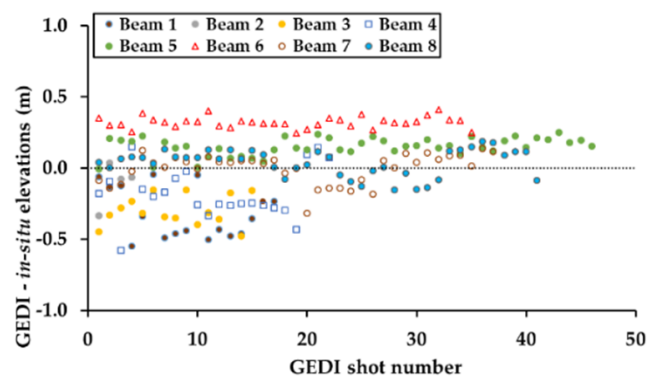

(g)

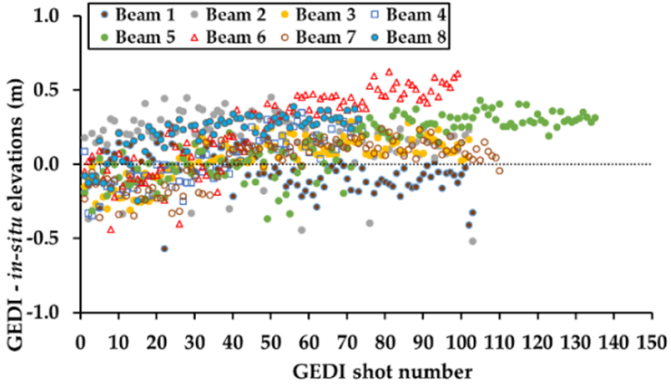

(b)

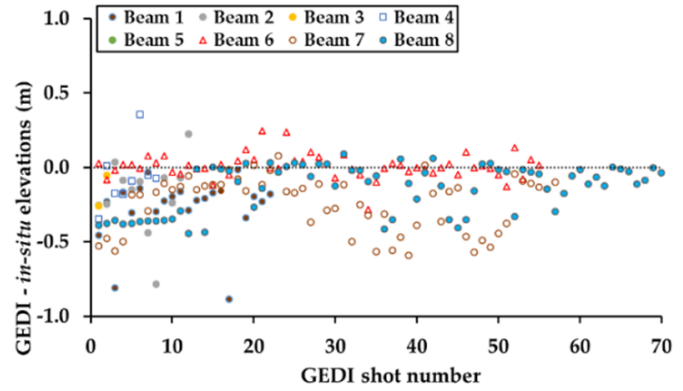

(d)

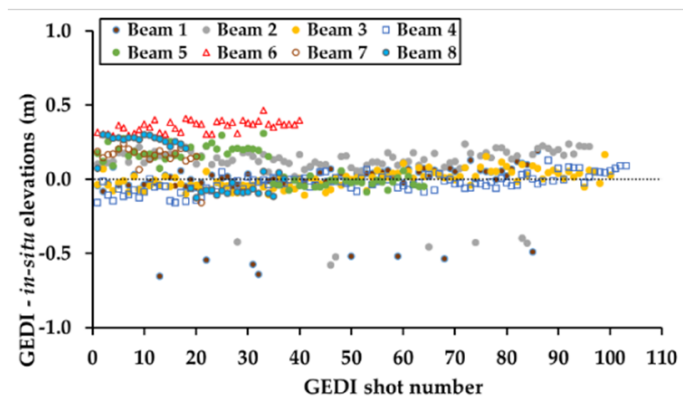

(f)

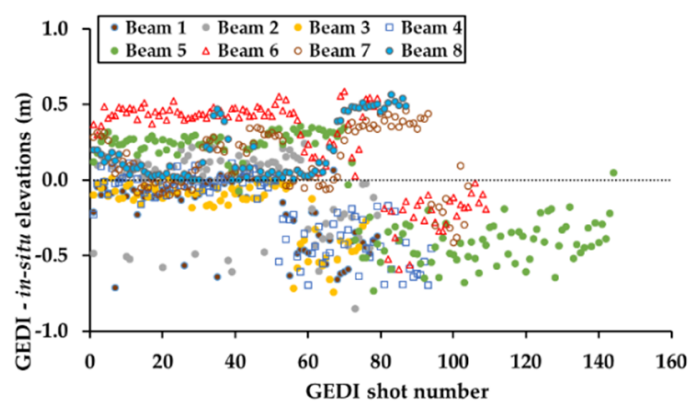

(h)

Figure A1. Difference between GEDI and in-situ elevations of all shots acquired over water for each lake on all dates, plotted for each beam (1 to 8). Abscissa = GEDI shot number. (a) Geneva, (b) Neuchâtel, (c) Zürich, (d) Obersee (Zürich), (e) Lucerne, (f) Walensee, (g) Sempach, and (h) Thun. 


\section{References}

1. Younger, P.L. Water: All That Matters; Teach Yourself: London, UK, 2015; ISBN 978-1-78539-007-4.

2. Schewe, J.; Heinke, J.; Gerten, D.; Haddeland, I.; Arnell, N.W.; Clark, D.B.; Dankers, R.; Eisner, S.; Fekete, B.M.; Colón-González, F.J.; et al. Multimodel assessment of water scarcity under climate change. Proc. Natl. Acad. Sci. USA 2014, 111, 3245-3250. [CrossRef] [PubMed]

3. Hirabayashi, Y.; Mahendran, R.; Koirala, S.; Konoshima, L.; Yamazaki, D.; Watanabe, S.; Kim, H.; Kanae, S. Global flood risk under climate change. Nat. Clim. Chang. 2013, 3, 816-821. [CrossRef]

4. Jiménez Cisneros, B.E.; Oki, T.; Arnell, N.W.; Benito, G.; Cogley, J.G.; Döll, P.; Jiang, T.; Mwakalila, S.S. Freshwater Resources. In Climate Change 2014 Impacts, Adaptation, and Vulnerability; Field, C.B., Barros, V.R., Dokken, D.J., Mach, K.J., Mastrandrea, M.D., Eds.; Cambridge University Press: Cambridge, UK, 2014; pp. 229-270. ISBN 978-1-107-41537-9.

5. Calmant, S.; Seyler, F. Continental surface waters from satellite altimetry. Comptes Rendus Geosci. 2006, 338, 1113-1122. [CrossRef]

6. Shiklomanov, A.I.; Lammers, R.B.; Vörösmarty, C.J. Widespread decline in hydrological monitoring threatens Pan-Arctic research. Eos 2002, 83, 13. [CrossRef]

7. Jiang, L.; Nielsen, K.; Andersen, O.B.; Bauer-Gottwein, P. CryoSat-2 radar altimetry for monitoring freshwater resources of China. Remote Sens. Environ. 2017, 200, 125-139. [CrossRef]

8. Birkett, C.M. The contribution of TOPEX/POSEIDON to the global monitoring of climatically sensitive lakes. J. Geophys. Res. 1995, 100, 25179. [CrossRef]

9. Birkett, C.M.; Beckley, B. Investigating the Performance of the Jason-2/OSTM Radar Altimeter over Lakes and Reservoirs. Mar. Geod. 2010, 33, 204-238. [CrossRef]

10. Crétaux, J.F.; Jelinski, W.; Calmant, S.; Kouraev, A.; Vuglinski, V.; Bergé-Nguyen, M.; Gennero, M.C.; Nino, F.; Abarca Del Rio, R.; Cazenave, A.; et al. SOLS: A lake database to monitor in the Near Real Time water level and storage variations from remote sensing data. Adv. Space Res. 2011, 47, 1497-1507. [CrossRef]

11. Crétaux, J.-F.; Biancamaria, S.; Arsen, A.; Bergé-Nguyen, M.; Becker, M. Global surveys of reservoirs and lakes from satellites and regional application to the Syrdarya river basin. Environ. Res. Lett. 2015, 10, 015002. [CrossRef]

12. Nielsen, K.; Stenseng, L.; Andersen, O.; Knudsen, P. The Performance and Potentials of the CryoSat-2 SAR and SARIn Modes for Lake Level Estimation. Water 2017, 9, 374. [CrossRef]

13. Frappart, F.; Papa, F.; Santos Da Silva, J.; Ramillien, G.; Prigent, C.; Seyler, F.; Calmant, S. Surface freshwater storage and dynamics in the Amazon basin during the 2005 exceptional drought. Environ. Res. Lett. 2012, 7. [CrossRef]

14. Frappart, F.; Biancamaria, S.; Normandin, C.; Blarel, F.; Bourrel, L.; Aumont, M.; Azemar, P.; Vu, P.-L.; Le Toan, T.; Lubac, B.; et al. Influence of recent climatic events on the surface water storage of the Tonle Sap Lake. Sci. Total Environ. 2018, 636, 1520-1533. [CrossRef] [PubMed]

15. Biancamaria, S.; Frappart, F.; Leleu, A.-S.; Marieu, V.; Blumstein, D.; Desjonquères, J.-D.; Boy, F.; Sottolichio, A.; Valle-Levinson, A. Satellite radar altimetry water elevations performance over a $200 \mathrm{~m}$ wide river: Evaluation over the Garonne River. Adv. Space Res. 2017, 59. [CrossRef]

16. Cretaux, J.-F.; Nielsen, K.; Frappart, F.; Papa, F.; Calmant, S.; Benveniste, J. Hydrological Applications of Satellite AltimetryRivers, Lakes, Man-Made Reservoirs, Inundated Areas. In Satellite Altimetry over Oceans and Land Surfaces; CRC Press: Boca Raton, FL, USA, 2017; pp. 459-504.

17. Birkett, C.; Reynolds, C.; Beckley, B.; Doorn, B. From research to operations: The USDA global reservoir and lake monitor. In Coastal Altimetry; Springer: Berlin/Heidelberg, Germany, 2011; pp. 19-50. ISBN 9783642127953.

18. Sulistioadi, Y.B.; Tseng, K.-H.; Shum, C.K.; Hidayat, H.; Sumaryono, M.; Suhardiman, A.; Setiawan, F.; Sunarso, S. Satellite radar altimetry for monitoring small rivers and lakes in Indonesia. Hydrol. Earth Syst. Sci. 2015, 19, 341-359. [CrossRef]

19. Donlon, C.; Berruti, B.; Buongiorno, A.; Ferreira, M.H.; Féménias, P.; Frerick, J.; Goryl, P.; Klein, U.; Laur, H.; Mavrocordatos, C.; et al. The Global Monitoring for Environment and Security (GMES) Sentinel-3 mission. Remote Sens. Environ. 2012, 120,37-57. [CrossRef] 
20. Shu, S.; Liu, H.; Beck, R.A.; Frappart, F.; Korhonen, J.; Xu, M.; Yang, B.; Hinkel, K.M.; Huang, Y.; Yu, B. Analysis of Sentinel-3 SAR altimetry waveform retracking algorithms for deriving temporally consistent water levels over ice-covered lakes. Remote Sens. Environ. 2020, 239, 111643. [CrossRef]

21. Huang, Q.; Li, X.; Han, P.; Long, D.; Zhao, F.; Hou, A. Validation and application of water levels derived from Sentinel-3A for the Brahmaputra River. Sci. China Technol. Sci. 2019, 62, 1760-1772. [CrossRef]

22. Normandin, C.; Frappart, F.; Diepkilé, A.T.; Marieu, V.; Mougin, E.; Blarel, F.; Lubac, B.; Braquet, N.; Ba, A. Evolution of the performances of radar altimetry missions from ERS-2 to Sentinel-3A over the Inner Niger Delta. Remote Sens. 2018, 10, 833. [CrossRef]

23. Bogning, S.; Frappart, F.; Blarel, F.; Niño, F.; Mahé, G.; Bricquet, J.P.; Seyler, F.; Onguéné, R.; Etamé, J.; Paiz, M.C.; et al. Monitoring water levels and discharges using radar altimetry in an ungauged river basin: The case of the Ogooué. Remote Sens. 2018, 10, 350. [CrossRef]

24. Schutz, B.E.; Zwally, H.J.; Shuman, C.A.; Hancock, D.; DiMarzio, J.P. Overview of the ICESat Mission. Geophys. Res. Lett. 2005, 32, L21S01. [CrossRef]

25. Dubayah, R.; Blair, J.B.; Goetz, S.; Fatoyinbo, L.; Hansen, M.; Healey, S.; Hofton, M.; Hurtt, G.; Kellner, J.; Luthcke, S.; et al. The Global Ecosystem Dynamics Investigation: High-resolution laser ranging of the Earth's forests and topography. Sci. Remote Sens. 2020, 1, 100002. [CrossRef]

26. Baghdadi, N.N.; El Hajj, M.; Bailly, J.-S.; Fabre, F. Viability Statistics of GLAS/ICESat Data Acquired Over Tropical Forests. IEEE J. Sel. Top. Appl. Earth Obs. Remote Sens. 2014, 7, 1658-1664. [CrossRef]

27. Abdallah, H.; Bailly, J.-S.; Baghdadi, N.; Lemarquand, N. Improving the assessment of ICESat water altimetry accuracy accounting for autocorrelation. ISPRS J. Photogramm. Remote Sens. 2011, 66, 833-844. [CrossRef]

28. Baghdadi, N.; Lemarquand, N.; Abdallah, H.; Bailly, J.S. The Relevance of GLAS/ICESat Elevation Data for the Monitoring of River Networks. Remote Sens. 2011, 3, 708-720. [CrossRef]

29. Lehner, B.; Döll, P. Development and validation of a global database of lakes, reservoirs and wetlands. J. Hydrol. 2004, 296, 1-22. [CrossRef]

30. Dubayah, S.L.R. GEDI L1B Geolocated Waveform Data Global Footprint Level V001; National Aeronautics and Space Administration: Washington, DC, USA, 2020.

31. Dubayah, S.L.R. GEDI L2A Elevation and Height Metrics Data Global Footprint Level V001; National Aeronautics and Space Administration: Washington, DC, USA, 2020.

32. Dubayah, S.L.R. GEDI L2B Canopy Cover and Vertical Profile Metrics Data Global Footprint Level V001; National Aeronautics and Space Administration: Washington, DC, USA, 2020.

33. Baghdadi, N.; le Maire, G.; Fayad, I.; Bailly, J.S.; Nouvellon, Y.; Lemos, C.; Hakamada, R. Testing Different Methods of Forest Height and Aboveground Biomass Estimations from ICESat/GLAS Data in Eucalyptus Plantations in Brazil. IEEE J. Sel. Top. Appl. Earth Obs. Remote Sens. 2014, 7, 290-299. [CrossRef]

34. Marti, U. Modelling of differences of height systems in Switzerland. Gravity Geoid 2002, 264, 379-383.

35. Oesch, D.; Jaquet, J.-M.; Klaus, R.; Schenker, P. Multi-scale thermal pattern monitoring of a large lake (Lake Geneva) using a multi-sensor approach. Int. J. Remote Sens. 2008, 29, 5785-5808. [CrossRef]

36. Lemmin, U.; D'Adamo, N. Summertime winds and direct cyclonic circulation: Observations from Lake Geneva. Ann. Geophys. 1996, 14, 1207-1220. [CrossRef]

37. Urban, T.J.; Schutz, B.E.; Neuenschwander, A.L. A Survey of ICESat Coastal Altimetry Applications: Continental Coast, Open Ocean Island, and Inland River. Terr. Atmos. Ocean. Sci. 2008, 19, 1-19. [CrossRef]

38. Breiman, L. Random forests. Mach. Learn. 2001, 45, 5-32. [CrossRef]

(C) 2020 by the authors. Licensee MDPI, Basel, Switzerland. This article is an open access article distributed under the terms and conditions of the Creative Commons Attribution (CC BY) license (http://creativecommons.org/licenses/by/4.0/). 